\title{
Homogenization and Seismic Assessment: Review and Recent Trends
}

\author{
Paulo B. Lourenço ${ }^{*}$ and Gabriele Milani ${ }^{\dagger}$ \\ * Professor, ISISE, Department of Civil Engineering, University of Minho, \\ Azurém, 4800-058 Guimarães, Portugal. E-mail: pbl@civil.uminho.pt. \\ Phone: +351 253510 200. Fax: +351 253510217. \\ ${ }^{\dagger}$ Assistant Professor, Politecnico di Milano, Piazza Leonardo da Vinci 32, \\ 20133 Milan, Italy
}

\begin{abstract}
The mechanics of masonry structures has been for long underdeveloped in comparison with other fields of knowledge. Presently, non-linear analysis is a popular field in masonry research and advanced computer codes are available for researchers and practitioners. The chapter presents a discussion of masonry behaviour and clarifies how to obtain the non-linear data required by the computations. The chapter also addresses different homogenisation techniques available in the literature in the linear and rigid-plastic case, aiming at defining a catalogue and at discussing the advantages and disadvantages of the different approaches. Special attention is given to stress assumed models based either on a polynomial expansion of the micro-stress field or in the discretization of the unit cell by means of a few constant stress finite elements CST with joints reduced to interfaces. Finally, the aspects of seismic assessment are presented and case studies involving the use of macro-block analysis, static (pushover) analysis and time integration analysis are discussed.
\end{abstract}

Keywords: masonry, non-linear data, homogenisation, limit analysis, Finite Elements, seismic assessment

\section{Homogenization Theory, Basic Assumptions}

This section briefly recalls the basis of the theory of homogenization applied to masonry structures, with particular emphasis on running bond texture. Consider a masonry wall $\Omega$, constituted by the periodic arrangements of masonry units and mortar joints as shown in Figure 1. The periodicity 

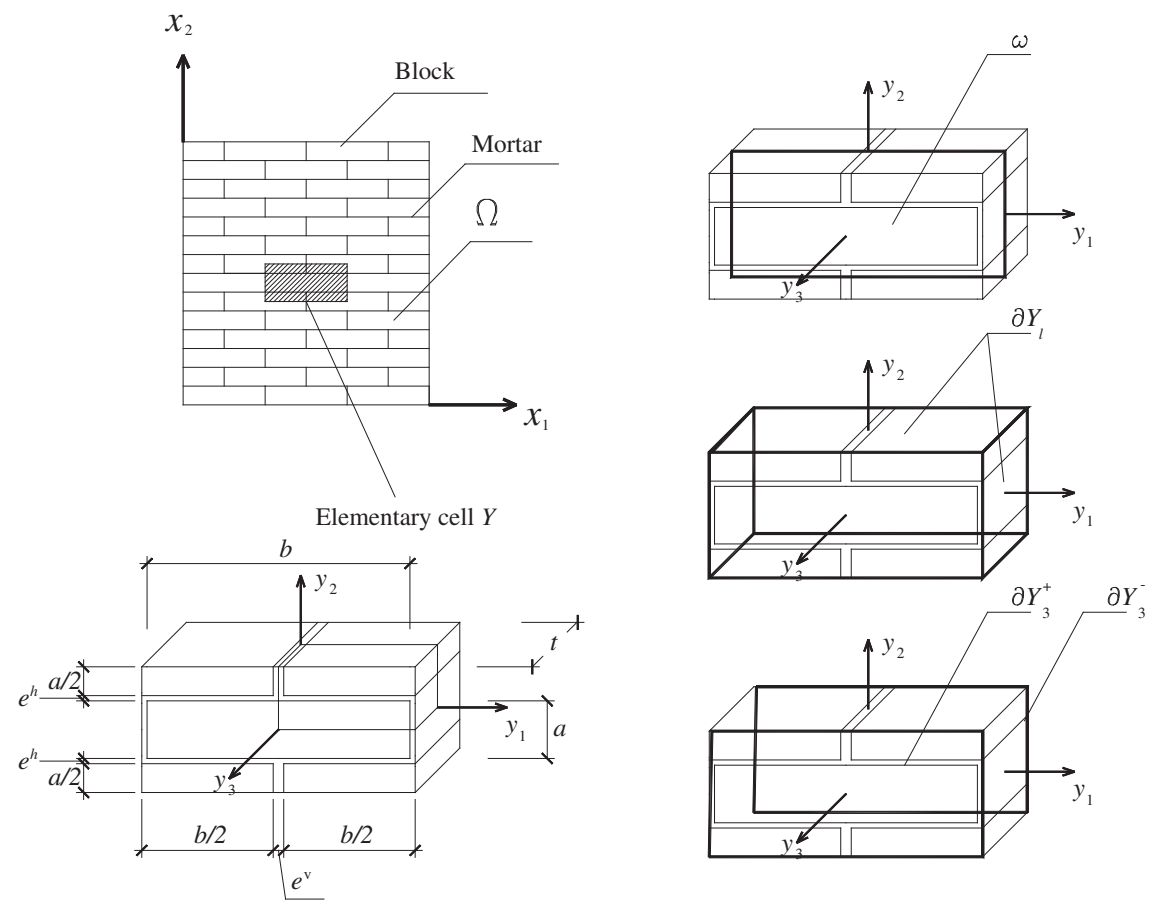

Figure 1. Representative Element of Volume (REV) for running bond masonry

allows to regard $\Omega$ as the repetition of a representative element of volume $Y$ (REV or elementary cell).

Let $\mathbf{x}=\left[x_{1}, x_{2}\right]$ be a frame of reference for the global description of $\Omega$ (macroscopic scale) and $\mathbf{y}=\left[y_{1}, y_{2}, y_{3}\right]$ a frame of reference for $Y$. The $Y$ module is defined as $Y=\omega \times\left[-\frac{t}{2}, \frac{t}{2}\right]$, where $Y \in \mathfrak{R}^{3}$ is the elementary cell and $\omega \in \mathfrak{R}^{2}$ represents the middle plane of the plate (Caillerie, 1984). The $\partial Y$ boundary surface of the elementary cell is shown also in Figure 1.

The basic idea of homogenization consists in introducing averaged quantities representing the macroscopic stress and strain tensors (denoted here respectively as $\mathbf{E}$ and $\boldsymbol{\Sigma}$ ), as follows:

$$
\mathbf{E}=\langle\boldsymbol{\epsilon}\rangle=\frac{1}{V} \int_{Y} \boldsymbol{\epsilon}(\mathbf{u}) \mathrm{d} Y \quad \boldsymbol{\Sigma}=\langle\boldsymbol{\sigma}\rangle=\frac{1}{V} \int_{Y} \boldsymbol{\sigma} \mathrm{d} Y
$$

where $V$ stands for the volume of the elementary cell, $\boldsymbol{\epsilon}$ and $\boldsymbol{\sigma}$ stand for 
the local quantities (stresses and strains respectively) and $\langle *\rangle$ is the average operator.

According to Anthoine (1995) and Cecchi et al. (2005) the homogenization problem in the linear elastic range in presence of coupled membranal and flexural loads, under the assumption of the Kirchhoff-Love plate theory, can be written as follows:

$$
\left.\begin{array}{ll}
\operatorname{div} \boldsymbol{\sigma}=\mathbf{0} & (a) \\
\boldsymbol{\sigma}=\boldsymbol{a}(\boldsymbol{y}) \boldsymbol{\epsilon} & (b) \\
\boldsymbol{\epsilon}=\mathbf{E}+y_{3} \boldsymbol{\chi}+\operatorname{sym}\left(\operatorname{grad} \mathbf{u}^{p e r}\right) & (c) \\
\boldsymbol{\sigma} \mathbf{e}_{3}=0 \text { on } \partial Y_{3}^{+} \text {and } \partial Y_{3}^{-} & (d) \\
\boldsymbol{\sigma} \mathbf{n} \text { antiperiodic on } \partial Y_{l} & (e) \\
\mathbf{u}^{\text {per }} \text { periodic on } \partial Y_{l} & (f)
\end{array}\right\}
$$

where $\boldsymbol{\sigma}$ is the microscopic stress tensor (micro-stress), $\mathbf{u}^{\text {per }}$ is a $\omega$-periodic displacement field, $\mathbf{E}$ is the macroscopic in-plane strain tensor, $\boldsymbol{\chi}$ is the outof-plane strain tensor (curvature tensor), $\boldsymbol{a}(\boldsymbol{y})$ represents a $\omega$-periodic linear elastic constitutive law for the components (masonry units and mortar), as given in equation (2b). Equation (2a) represents the micro-equilibrium for the elementary cell with zero body forces, usually neglected in the framework of homogenization.

Furthermore, in equation (2c), the micro-strain tensor $\boldsymbol{\epsilon}$ is obtained as a linear combination among macroscopic $\mathbf{E}$ and $\chi$ tensors and a periodic strain field. $\mathbf{E}$ and $\boldsymbol{\chi}$ tensors are related to $\boldsymbol{a}(\boldsymbol{y})$ represents a $\omega$-periodic linear elastic constitutive law for the components (masonry units and mortar), as given in equation (2b). Equation (2a) represents the micro-equilibrium for the elementary cell with zero body forces, usually neglected in the framework of homogenization. The macroscopic displacement field components $U_{1}\left(x_{1}, x_{2}\right), U_{2}\left(x_{1}, x_{2}\right)$ and $U_{3}\left(x_{1}, x_{2}\right)$ by means of the classic relations $\mathbf{E}_{\alpha \beta}=\frac{1}{2}\left(U_{\alpha, \beta}+U_{\beta, \alpha}\right)$, with $\mathbf{E}_{i 3}=0$, and $\chi_{\alpha \beta}=-U_{3, \alpha \beta}$ with $\chi_{i 3}=0$, $\alpha, \beta=1,2$ and $i=1,2,3$.

Macroscopic homogenized membrane and bending constants can be obtained solving the elastostatic problem (2) and making use of the classic relations:

$$
\begin{gathered}
\mathbf{N}=\langle\boldsymbol{\sigma}\rangle^{*}=\mathbf{A} \mathbf{E}+\mathbf{A} \boldsymbol{\chi} \\
\mathbf{M}=\left\langle y_{3} \boldsymbol{\sigma}\right\rangle^{*}=\mathbf{B}^{\mathbf{T}} \mathbf{E}+\mathbf{D} \boldsymbol{\chi}
\end{gathered}
$$

where $\mathbf{A}, \mathbf{B}$, and $\mathbf{D}$ are the constitutive homogenized plate tensors. Usually, the elementary cell has a central symmetry, hence $\mathbf{B}=\mathbf{0}$. As a rule, a solution for the problem given by equation (2) can be obtained using standard FE packages, as suggested for the in-plane case by Anthoine (1995). 
The governing equations in the non-linear case are formally identical to equation (2) provided that a non-linear stress-strain law for the constituent materials is assumed. Extensions to the non-linear case have been provided by e.g. Luciano and Sacco (1997); Pegon and Anthoine (1997); Massart (2003); Massart et al. (2004); Zucchini and Lourenço (2004), etc.

\subsection{Closed-form and simplified solutions in the linear elastic range}

This section briefly recalls some of the most popular simplified approaches that appeared in the past in the technical literature for obtaining homogenized elastic moduli for masonry. Since the elastostatic problem given in equation (2) cannot be solved in closed form for running bond masonry, several simplifications were assumed in order to obtain "easily" homogenized elastic moduli.

Two-step approaches. One of the first ideas presented, Pande et al. (1989) and Maier et al. (1991), was to substitute the complex geometry of the basic cell with a simplified geometry, so that a closed-form solution for the homogenization problem was possible.

In particular, Pande et al. (1989) presented a model in which a two-step stacked system with alternative isotropic layers was considered (Figure 2). In this way, a so called "two-step homogenization" was obtained. In the first step, a single row of masonry units and vertical mortar joints were taken into consideration and homogenized as a layered system. In the second step, the "intermediate" homogenized material was further homogenized with horizontal joints in order to obtain the final material. In this manner, a very simple mechanical system constituted by elastic springs was obtained and explicit formulas based on classical elasticity concepts were presented.

Obviously, this simplification leads:

1. To underestimate the horizontal stiffness of the homogenized material, since no information on the texture (running bond, stack bond, Flemish bond, etc.) is considered. Furthermore, the inability of the model to consider the regular offset of vertical mortar joints belonging to two consecutive layered unit courses results in significant errors in the case of non-linear analysis;

2. To obtain a homogenized material different if the steps of homogenization are inverted (i.e. if bed joints and masonry units are homogenized in the first step).

Following the idea of a multi-step approach, many other models involving different approximations and ingenious assumptions have been sought, with an increasing large number of papers in the recent years (Pietruszczak and 
(a)

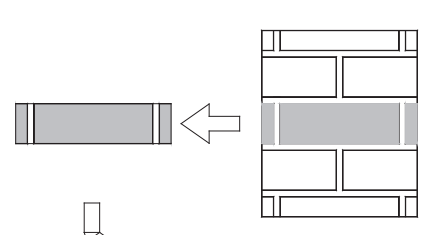

$\infty$
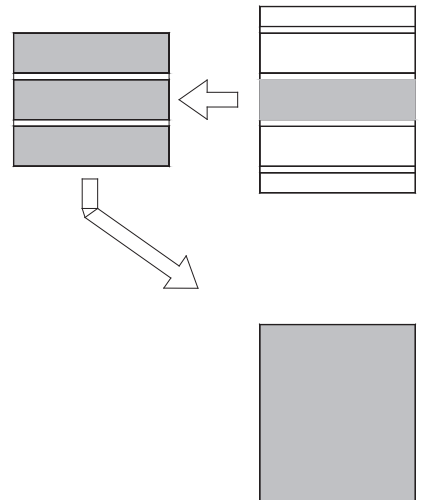

(b)
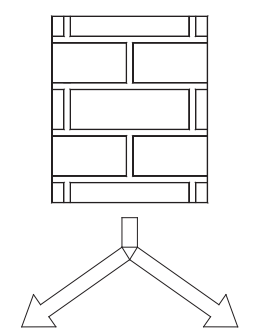

First step
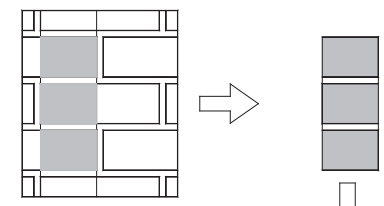

Second step

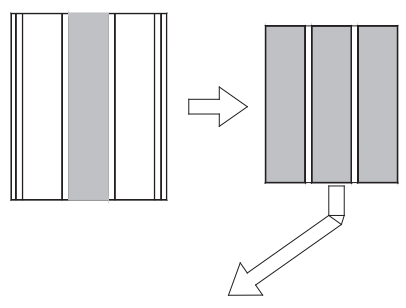

Homogenized material

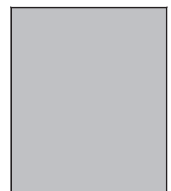

Figure 2. Two-step homogenization 
Niu, 1992), where a two-stage homogenization procedure was employed with the head joints considered as uniformly dispersed elastic inclusions and the bed joints assumed to represent a set of continuous weakness.

Reduction of joints to interfaces. A different approach, proposed by de Felice (1995) and Cecchi and Sab (2002), is based on the reduction of joints to interfaces. This idea arose from the observation that masonry units are generally much stiffer than mortar and joints show a small thickness if compared with the size of masonry units.

These studies resulted in the definition of the homogenized masonry constitutive function by means of the introduction of several parameters that measure smallness:

3. $\epsilon$ (scale parameter $) \rightarrow 0$, which represents the ratio between the size of the cell and the dimension of the overall panel;

4. $\xi$, representing the ratio between the Young's modulus of the mortar $E_{m}$ and the Young's modulus of the masonry unit $E_{b}\left(\xi=\frac{E_{m}}{E_{b}}\right)$;

5. $\varphi$, representing the ratio between the thickness of the joints e and the size of the characteristic module $a\left(\varphi=\frac{e}{a}\right)$.

$\xi$ and $\varphi$ are parameters that take into account the effects of joint sizes and the ratio of deformability of mortar and block. For fixed elastic tensors of both block and mortar and for fixed geometric parameters $a, b, t$ (defined in 1), the so-called "asymptotic case" is obtained when $\xi \rightarrow 0$ and $\varphi \rightarrow 0$. If $\varphi$ tends to zero, the joint becomes and interface, whereas if $\xi$ tends to zero the mortar becomes infinitely deformable with respect to the unit. Therefore, the typology of asymptotic problem depends on how $\xi$ and $\varphi$ tend to zero.

A first simplification usually introduced adopts $\xi=\xi(\varphi)$ and additionally, $\lim _{\varphi \rightarrow 0} \xi(\varphi) \varphi^{-1}=\rho \neq 0$. Such asymptotic problem shows cohesive zero thickness interfaces between the masonry units with possible jump of the displacement field. Hence, the field problem may be formulated with reference only to the $\mathbf{a}^{a}$ elastic tensor of the masonry unit with discontinuity at the interfaces, where the constitutive function is a linear relation between the stresses on the unit surfaces and the jump of the displacement field. Both in de Felice (1995) and Cecchi and Sab (2002), elastic springs with diagonal constitutive tensor $\mathbf{K}$ for the joints are used, so introducing a simplification related to the fact that Poisson effect of the joint is neglected. In particular $\mathbf{K}$ takes the following explicit form:

$$
\mathbf{K}=\frac{1}{e}\left(\mu^{M} \mathbf{I}+\left(\mu^{M}+\lambda^{M}\right)(\mathbf{n} \otimes \mathbf{n})\right)
$$

where $e$ is the thickness of the joint, $\mathbf{n}$ is the normal to the interface, and $\mu^{M}, \lambda^{M}$ are the Lamé constants of mortar. 
(a)

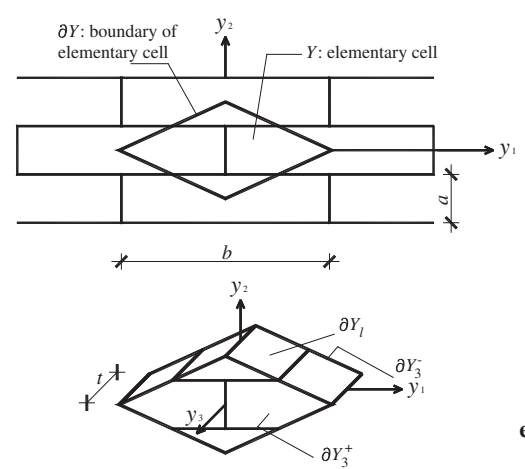

(b)

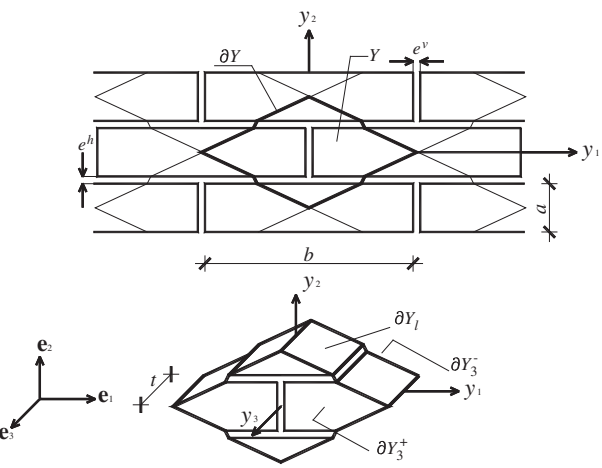

Figure 3. unit cell utilized in de Felice (1995) and Cecchi and Sab (2002). Left: joints reduced to interfaces. Right: actual thickness of the joints.

De Felice (1995) assumed also rigid masonry units, in order to reduce further the complexity of the problem. In this way, see Figure 3-a, this author showed that the problem given by equation (2) can be solved in closed form for running bond masonry and permits to obtain analytical formulas for the homogenized elastic constants, which depend only on the geometry of the elementary cell and on the mechanical properties of joints.

Following this idea, Cecchi and Sab (2002) proposed a multi-parameter homogenization study for the 2D and the 3D in-plane case, removing the hypothesis of rigid masonry units (Figure 3-b). The finite thickness of the joints was considered in an approximated way only in the constitutive relation of the interfaces. A symbolic FE procedure was adopted, in which the elementary cell was discretized by means of a coarse triangular mesh. Here the term symbolic is use to indicate that the homogenization problem was handled in symbolic form, using a mathematical software. In this way, these authors were able to find "quasi-analytical" formulas.

The disadvantages of this approach are the following:

1. The reduction of joints to interfaces, may strongly reduce the accuracy of the results in presence of thick mortar joints and in presence of $\xi$ ratios tending to zero Cecchi et al. (2005).

2. The introduction of elastic masonry units leads to formulas derived from symbolic FE procedures and does not allow solving analytically the homogenization problem.

3. A possible development of the method in the non-linear range can result in non-negligible errors with respect to finite element approaches 
and experimental evidences, since the role of joint thickness is lost in the simplifications assumed.

FE procedures. Anthoine (1995) was the first to suggest the utilization of standard FE codes for solving the homogenization problem given by equation (2) in the case of both stacked and running bond masonry. Anthoine $(1995,1997)$ and Lourenço (1997) also underlined that homogenized moduli depend on the order of the steps and 3D effects are always present.

Cecchi et al. (2005) applied FE procedures to masonry out-of-plane loaded and stressed that:

1. Flexural moduli may significantly differ from membrane moduli, especially in the presence of weak mortar joints. As a consequence, Kirchhoff-Love orthotropic homogenized coefficients cannot be obtained simply by integration of membrane moduli.

2. Cohesive interface closed-form solutions give unreliable results when the $\xi$ ratio is small.

The classical assumptions adopted in the FE method applied to homogenization are the following:

1. Perfect continuity between units and mortar;

2. The periodic displacement that has to be imposed fulfils the constant/linear assumption, at the boundary of the cell, of the macroscopic kinematic descriptors $\mathbf{E}$ and $\boldsymbol{\chi}$.

In this way, considering only a macroscopic strain tensor $\mathbf{E}$ acting, suitable boundary conditions (Figure 4 ) for $\mathbf{u}^{\text {per }}$ periodic and $\boldsymbol{\sigma} \mathbf{n}$ anti-periodic on $\partial Y_{l}$ (which represents the boundary of the module orthogonal to the middle plane) are imposed, meaning that the elastostatic problem can be formulated only on $Y$. It is worth noting that several engineering approaches recently presented in the technical literature do not satisfy exactly this hypothesis (Lopez et al., 1999; Zucchini and Lourenço, 2002). In this case, the symmetry of the cell allows to simplify the numerical model and permits to discretize only $1 / 4$ of the elementary cell.

The advantages of the adoption of a FE technique include:

1. The FE solution approximates the actual solution for a suitable refined mesh;

2. Mortar joints thickness is taken into account for the evaluation of the homogenized moduli. This leads to estimate numerically homogenized moduli that can differ from interface moduli;

3. The influence on the homogenized horizontal Young modulus, due to the masonry units staggering, is caught by the model, especially in presence of mortar joints with poor mechanical properties or nonlinear behaviour. 


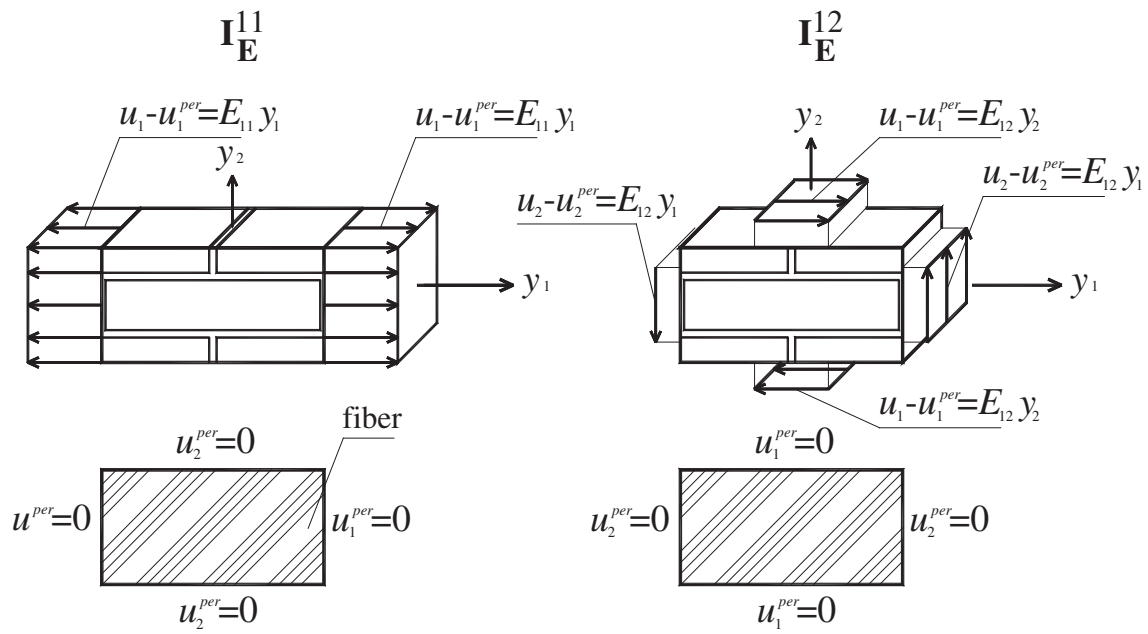

Figure 4. Applied displacement boundary conditions on the elementary cell.

On the other hand, the most severe limitation of the approach is that the computational cost of a $\mathrm{FE}$ procedure does not compete favourably with macroscopic approaches when non-linear problems are treated, since the homogenization field problem has to be solved for each Gauss point of each loading step. This leads to handle continuously a "two-size" FE problem (macroscopic and cell level), where the averaged results obtained at a cell level are utilized at a structural level (in the framework of non-linear numerical procedure).

\subsection{Simplified stress assumed FE discretization}

Simplified models based on a stress assumed FE discretization in the elastic range have been recently proposed by Milani et al. (2006a) and Milani (2011). Essentially, the approach relies into a rough FE discretization of the unit cell, where inside each element a polynomial interpolation of the stress field is a-priori given. Equilibrium inside each element and at the interface between contiguous elements and anti-periodicity conditions are imposed. The solution in the elastic range is simply achieved minimizing the total complementary energy stored into the unit cell, subjected to a certain number of equality constraints representing equilibrium and antiperiodicity.

As shown in Figure 5, one-fourth of the REV is sub-divided into nine 

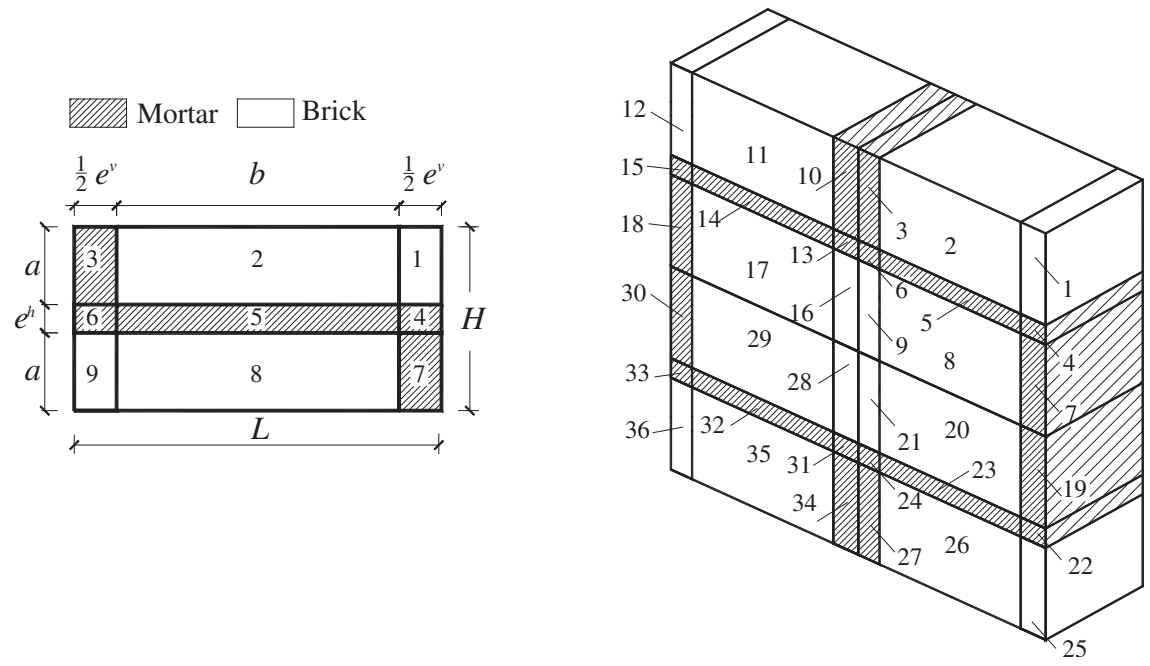

Figure 5. Subdivision in sub domains adopted: Left: subdivision and geometrical characteristics of one-fourth of the elementary cell, Right: subdivision into 36 sub-domains for the entire cell.

geometrical elementary entities (sub-domains), so that all the cell is subdivided into 36 sub-domains.

For each sub-domain, polynomial distributions of degree $(m)$ are a priori assumed for the stress components. The generic $i j$-th component can be written as follows:

$$
\sigma_{i j}^{(k)}=\mathbf{X}(\mathbf{y}) \mathbf{S}_{i j}^{T} \quad \mathbf{y} \in Y^{K}
$$

where:

$$
\begin{aligned}
& \text { - } \mathbf{X}(\mathbf{y})=\left\lfloor\begin{array}{lllllll}
1 & y_{1} & y_{2} & y_{1}^{2} & y_{1} y_{2} & y_{2}^{2} & \ldots
\end{array}\right\rfloor ; \\
& \text { - } \mathbf{S}_{i j}=\left[\begin{array}{lllllll}
S_{i j}^{(1)} & S_{i j}^{(2)} & S_{i j}^{(3)} & S_{i j}^{(4)} & S_{i j}^{(5)} & S_{i j}^{(6)} & \ldots
\end{array}\right] \text { is a vector of length } \\
& (\widetilde{N}) \quad\left(\widetilde{N}=\frac{m^{2}}{2}+\frac{3 m}{2}+1=\frac{(m+1)(m+2)}{2}\right) \text { representing the un- } \\
& \text { known stress parameters; } \\
& \text { - } Y^{k} \text { represents the } k^{\text {th }} \text { sub-domain. }
\end{aligned}
$$

The imposition of equilibrium with zero body forces inside every sub-domain, the continuity of the stress vector on interfaces and anti-periodicity of $\boldsymbol{\sigma} \mathbf{n}$ permit to strongly reduce the total number of independent stress parameters.

In particular, equilibrium has to be imposed everywhere inside each subdomain, i.e. $\sigma_{i j, j}(x)=0,, i=1,2 \forall(x, y) \in$ sub-domain. Since $\sigma_{i j}(x, Y)$ is a 
polynomial expression of degree $(m)$, a linear combination of its derivatives $(\operatorname{div} \boldsymbol{\sigma})$ is a polynomial of degree $(m-1)$. Therefore equilibrium inside each sub-domain leads to write $(2 N)$ linear independent equations in the stress coefficients, where $N=\frac{m^{2}}{2}+\frac{3 m}{2}+1=\frac{(m+1)(m+2)}{2}$.

(a)
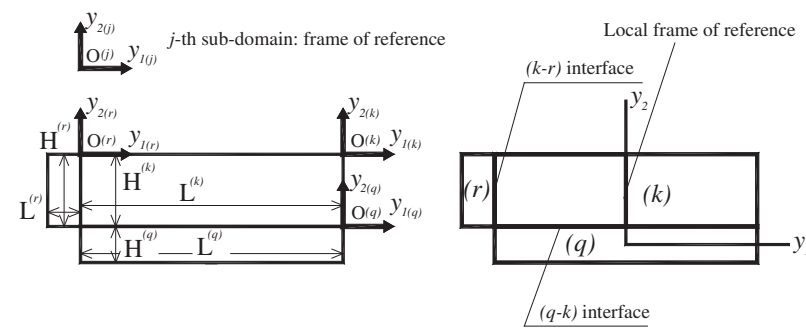

(c)

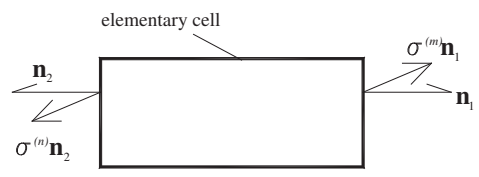

(b)

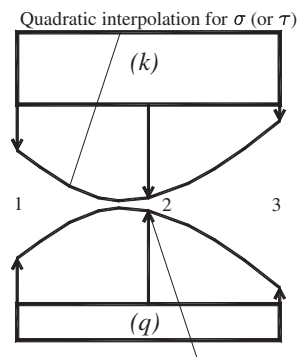

Equilibrium to check in 3 point

(d)

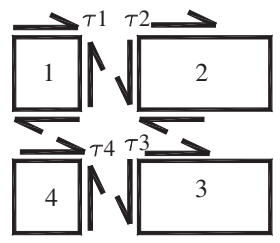

Figure 6. Contiguous sub-domains. -a: geometry and frame of reference of the sub-domains; -b: vertical/horizontal interfaces between adjacent subdomains; -c: anti-periodicity conditions on the unit cell; -d: linear dependence of some equilibrium equations.

A further reduction of the total unknowns is obtained a priori imposing the continuity of the stress vector on internal interfaces $\left(\sigma_{i j}^{(k)} n_{j}+\sigma_{i j}^{(r)} n_{j}=\right.$ $0, i=1,2)$ for every $(k)$ and $(r)$ contiguous sub-domains with a common interface of normal $\mathbf{n}(6)$. Being Eqs. (5) polynomial expressions of degree $(m)$ in the abscissa $s$ of the interface, other $2 N^{\prime}$ equations (where $N^{\prime}=$ $m+1)$ in $\hat{\mathbf{S}}^{(k)}$ and $\hat{\mathbf{S}}^{(r)}$ for each $(k \leftrightarrow r)$ interface can be written from (5), see Figure 6-b.

Finally anti-periodicity of $\boldsymbol{\sigma n}$ on $\partial V$ requires $2 N^{\prime}$ additional equations per pair of external faces $(m)(n)$ (Figure 6-c), i.e. it should be imposed that 
stress vectors $\boldsymbol{\sigma n}$ are opposite on opposite sides of $\partial V$ :

$$
\hat{\mathbf{X}}_{i j}^{(m)}(\mathbf{y}) \hat{\mathbf{S}}^{(m)} \mathbf{n}_{1}=-\hat{\mathbf{X}}_{i j}^{(n)}(\mathbf{y}) \hat{\mathbf{S}}^{(n)} \mathbf{n}_{2}
$$

Where $\mathbf{n}^{(m)}$ and $\mathbf{n}^{(n)}$ are oriented tensors of the external faces of the paired sub-domains $(m)(n)$.

To conclude, some elementary assemblage operations on the local variables (handled automatically) lead to write the stress vector inside every sub-domain as follows:

$$
\widetilde{\boldsymbol{\sigma}}^{(k)}=\widetilde{\mathbf{X}}^{(k)}(\mathbf{y}) \widetilde{\mathbf{S}} \quad k=1, \ldots, k^{\max }
$$

where:

- $\tilde{\boldsymbol{\sigma}}^{(k)}$ is the vector of membrane actions inside the $k^{\text {th }}$ sub-domain;

- $\widetilde{\mathbf{X}}^{(k)}$ is a $3 \times N_{u n}$ matrix which contains only geometrical coefficients; its elements are polynomial forms in the microscopic coordinate $\mathbf{y}$;

- $\widetilde{\mathbf{S}}$ is the vector (of length $N_{u n}$ ) of the total stress parameters unknown.

The equations written in order to satisfy internal equilibrium, equilibrium on interfaces and anti-periodicity of the stress vector lead to a system of equations $\mathbf{A} \mathbf{S}=\mathbf{0}$, where $\mathbf{S}$ is the vector of total stress parameters. Nevertheless, not all the rows of this system are linearly independent. This can be easily shown if four generic rectangular elements with four common interfaces and subjected only to constant non zero shear stress are considered, as reported in Figure 6-d. Internal equilibrium is a priori satisfied, whereas four equations for ensuring equilibrium on interfaces have to be written. Nevertheless, only three of these four equations are linear independent.

Finally, four different models of increasing accuracy $\left(\begin{array}{llll}P_{0} & P_{2} & P_{3} & P_{4}\end{array}\right)$ have been obtained increasing the degree of the polynomial expansion.

\subsection{Linear elastic case}

A preliminary study in the linear elastic range may be done considering the quadratic functional $\Pi$ of the complementary energy evaluated in the REV. With the stress-assumed discretization previously discussed, an approximation of $\Pi$ can be written as:

$$
\Pi^{*}=\sum_{k=1}^{k^{\max }} \int_{Y_{k}} \frac{1}{2} \widetilde{\mathbf{S}}^{T} \widetilde{\mathbf{X}}^{(k) T}(\mathbf{y}) \mathbf{C}^{b, m} \widetilde{\mathbf{X}}^{(k)} \widetilde{\mathbf{S}} \mathrm{d} Y_{k}-\sum_{j} \int_{S_{j}} \widetilde{\mathbf{S}}^{T} \widetilde{\mathbf{X}}^{(k) T} \overline{\mathbf{u}} \mathrm{d} S_{j}
$$

Where $\mathbf{C}^{b, m}$ is the compliance matrix of units or mortar joints and $\overline{\mathbf{u}}$ is the displacement imposed on the boundary $\partial Y$ of the elementary cell, representing a given macroscopic strain tensor $\mathbf{E}$. 
The minimization of the approximated expression of $\Pi$ leads to the following expression:

$$
\begin{aligned}
\nabla \Pi^{*}= & \left(\sum_{k=1}^{k^{\max }} \int_{Y_{k}} \widetilde{\mathbf{X}}^{(k) T}(\mathbf{y}) \mathbf{C}^{b, m} \widetilde{\mathbf{X}}^{(k)} \mathrm{d} Y_{k}\right) \widetilde{\mathbf{S}} \\
& \quad-\sum_{j} \int_{S_{j}} \widetilde{\mathbf{X}}^{(k) T}(\mathbf{y}) \overline{\mathbf{u}} \mathrm{d} S_{j} \\
= & \mathbf{C}^{\text {hom } \widetilde{\mathbf{S}}}-\overline{\mathbf{U}}=0
\end{aligned}
$$

which enables to find both $\widetilde{\mathbf{S}}$, by factorization of the matrix $\mathbf{C}^{\text {hom }}$ and $\boldsymbol{\Sigma}$, from integration of the local stress field.

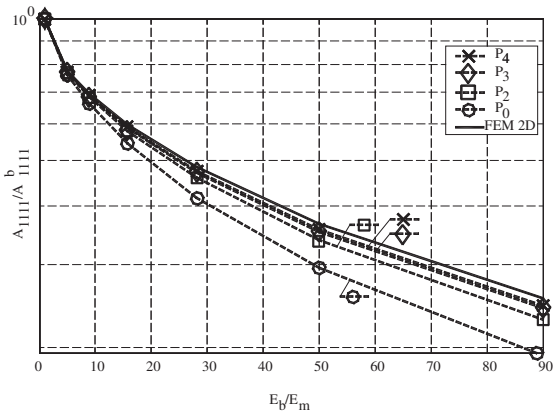

(c)

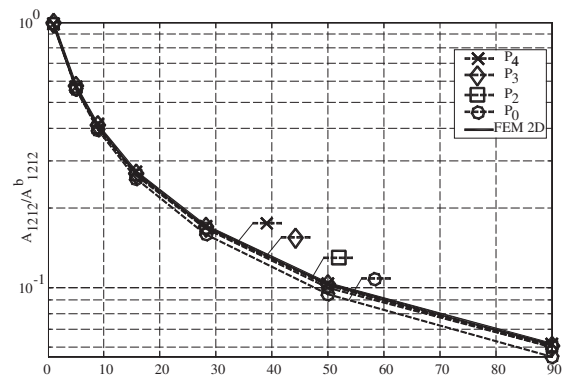

$\mathrm{E}_{\mathrm{b}} \mathrm{E}_{\mathrm{m}}$ (b)

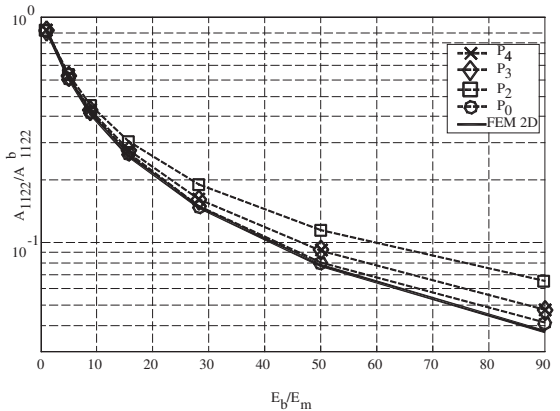

(d)

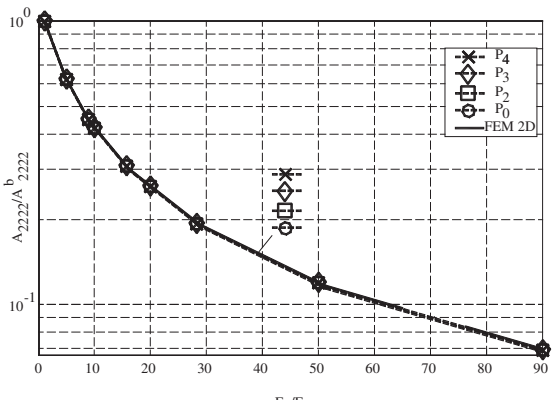

$\mathrm{E}_{\mathrm{b}} \mathrm{E}_{\mathrm{m}}$

Figure 7. Homogenised in-plane moduli. -a: $A_{1111}$ modulus; -b: $A_{1212}$ modulus; -c: $A_{1122}$ modulus; -d: $A_{2222}$ modulus.

A comparison between the elastic moduli provided by the model proposed and a standard numerical 2D FEM procedure, Anthoine (1995), is 
Table 1. Initial mechanical properties assumed for the elastic simulations reported in Figure 7.

\begin{tabular}{|c|c|c|}
\hline & $\begin{array}{c}\mathrm{E}\left[\mathrm{N} / \mathrm{mm}^{2}\right] \\
\text { Young modulus }\end{array}$ & $\begin{array}{c}\nu \\
\text { Poisson ratio }\end{array}$ \\
\hline unit & 11000 & 0.2 \\
\hline mortar & 2200 & 0.25 \\
\hline
\end{tabular}

presented in Figure 7. The dimensions of the units are assumed to be $250 \times 120 \times 55 \mathrm{~mm}^{3}$ (brick UNI5628/65) and the thickness of mortar joints is equal to $10 \mathrm{~mm}$. The initial mechanical characteristics of materials are reported in Table 1; the simulations are handled keeping the brick Young modulus $E_{b}$ constant and progressively reducing the mortar Young modulus $E_{m}$, so assuming a wide range of $E_{b} / E_{m}$ ratios (from 5 to 90 ), in order to simulate also historical brickwork. Homogenized $A_{i j h k}$ membrane moduli are represented varying $E_{b} / E_{m}$ ratio. The homogenized moduli are normalized versus the corresponding moduli of the brick. As it can be noticed, the provided moduli are reliable in a large range of $E_{b} / E_{m}$ ratios, even for the simplest model with constant stresses tensor $(P 0)$. Nevertheless, Figure 7-a shows that a progressively reduced accuracy of the $P 0$ model can be noticed for the $A_{1111}$ module, due to the presence of shear stresses in the bed joint.

\subsection{Constant Stress Triangular elements discretization of the unit cell}

In Milani (2011), an alternative static model relying into the subdivision of the unit cell into 24 constant stress triangular elements and joints reduced to interfaces is presented. Due to the very limited number of optimization variables involved, the model can be handled also without the assistance of a computer.

Joints are reduced to interfaces with zero thickness and blocks are discretized by means of a coarse mesh constituted by three-noded plane-stress elements, Figure 8 . The choice of meshing $1 / 4$ of the brick through at least 3 triangular elements is due to the need of reproducing the presence of shear stress in the bed joint (element 2 in Figure 8) in horizontal stretching. All the non-linearity in the RVE is concentrated exclusively on interfaces between adjoining elements both on brick and joint. Brick-brick interfaces allow, at least in principle, the reproduction of blocks failure. The six CST elements used for the discretization of the upper-right $1 / 4$ of the REV are indicated in Figure 14 as 1, 2, 3, 1', 2', 3'.

In the model, the non-dimensional geometrical coefficient $\rho$ indicates the 

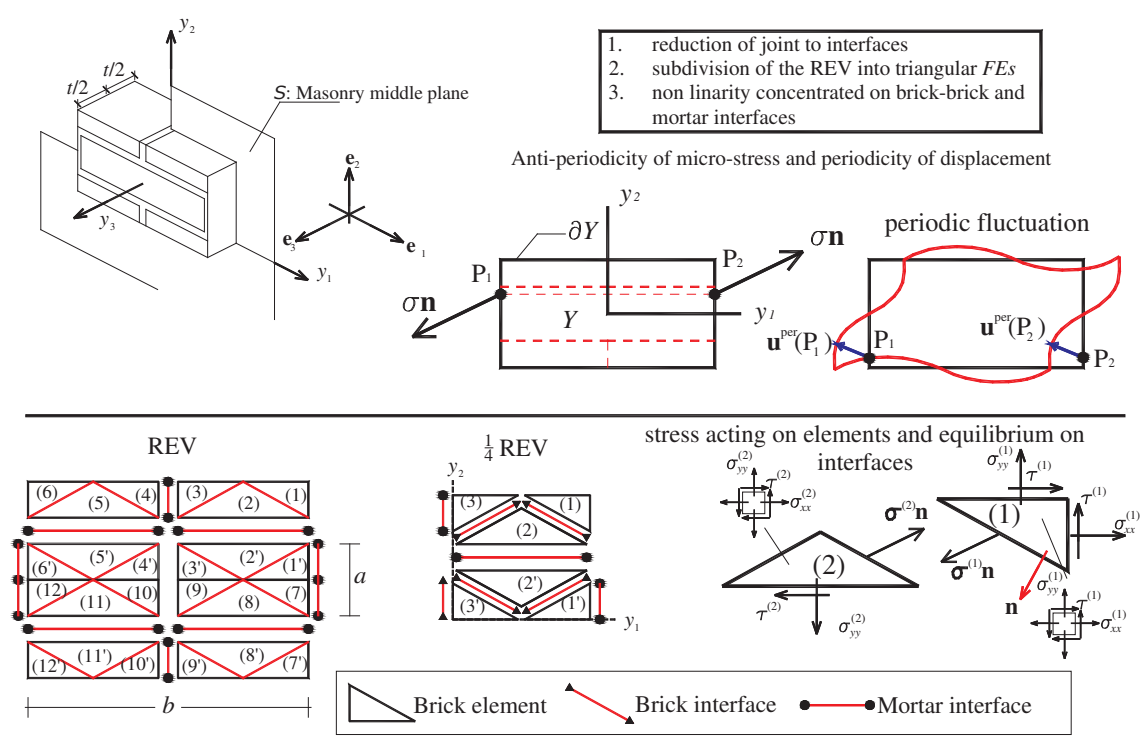

Figure 8. The micro-mechanical model proposed. Subdivision of the REV into 24 CST triangular elements (and $1 / 4$ into 6 elements) and antiperiodicity of the micro-stress field.

ratio between brick semi-length and height, i.e. $\rho=b / 2 a$ and the superscript $(n)$, with $n$ positive integer, a stress component belonging to the $n$-th element. In this way, assuming a plane-stress condition, the Cauchy stress tensor inside the $n$-th CST element $\boldsymbol{\sigma}^{(n)}$ is constituted by the components $\sigma_{x x}^{(n)}$ (horizontal stress), $\sigma_{y y}^{(n)}$ (vertical stress) and $\tau^{(n)}$ (shear stress).

Within the static approach of limit analysis, equilibrium inside each element is a priori satisfied, $\operatorname{div} \sigma=0$. On the contrary, two equality constraints involving Cauchy stress tensor components of triangular elements must be imposed for each internal interface between adjoining elements.

It can be shown that the imposition of equilibrium on interfaces is represented by a set of 10 equations (being 5 the interfaces for $1 / 4$ of the REV) in 18 unknowns (three stress components for each triangular element).

Having in mind to analyze masonry macroscopic behaviour under combined states of stress acting on its middle plane, all the REV must be considered, as depicted schematically in Figure 8. Anti-periodicity constrains for the stress vector field are written on couples of triangles 1-6, 1'-6', 7-12, 7'-12', 1-7', 3-9', 4-10', 6-12'.

When the whole cell problem is considered, independent variables are 
represented by stresses acting on the triangular elements ( 3 unknowns per element, i.e. 72 unknowns per REV) and the three homogenized stresses $\Sigma_{x x}, \Sigma_{y y}$ and $\Sigma_{x y}$ (75 total optimization variables).

$\Sigma_{x x}, \Sigma_{y y}$ and $\Sigma_{x y}$ are linked with local stress variables by means of the following set of three equations:

$$
\begin{aligned}
& \Sigma_{x x}=\frac{1}{A_{C}} \sum_{i=1}^{N^{t r}} A_{t r}^{(i)} \sigma_{x x}^{(i)} \\
& \Sigma_{y y}=\frac{1}{A_{C}} \sum_{i=1}^{N^{t r}} A_{t r}^{(i)} \sigma_{y y}^{(i)} \\
& \Sigma_{x y}=\frac{1}{A_{C}} \sum_{i=1}^{N^{t r}} A_{t r}^{(i)} \tau^{(i)}
\end{aligned}
$$

Where, apart quantities already introduced, $A_{t r}^{(i)}$ is the area of the $i$-th CST element, $N^{t r}$ is the total number of elements in the unit cell and $A_{C}$ is the total area of the unit cell.

From equilibrium equations, anti-periodicity and (10) a set of linear equations in both the elastic and rigid-plastic problem is obtained.

When dealing with the elastic case, membrane elastic homogenized moduli may be obtained in the same way followed for the polynomial expansion shown in the previous case, i.e. minimizing the complementary energy in the unit cell. In this case, the complementary energy assumes the following quadratic form:

$$
\begin{gathered}
\Pi^{*}=\frac{1}{2} \sum_{i=1}^{N^{t r}} A_{t r}^{(i)}\left[\frac{\sigma_{x x}^{(i)^{2}}}{E_{b}}+2 \nu_{b} \frac{\sigma_{x x}^{(i)} \sigma_{y y}^{(i)}}{E_{b}}+\frac{\sigma_{y y}^{(i)^{2}}}{E_{b}}+\frac{\tau^{(i)^{2}}}{G_{b}}\right] \\
+\frac{1}{2} \sum_{i=1}^{N^{I}} A_{I}^{(i)^{2}}\left[\frac{\sigma_{n}^{(i)^{2}}}{E_{m}}+\frac{\tau^{(i)^{2}}}{G_{m}}\right]-A_{C} \Sigma_{i j} E_{i j}
\end{gathered}
$$

Where $N^{I}$ is the total number of mortar interfaces, $A_{I}^{(i)}$ is the area of the $i$-th mortar interface and $\Sigma_{i j} E_{i j}$ is a summation saturating indices $i$ and $j$ (assuming either value $x$ or $y$ ) and $E_{i j}$ is a prescribed macroscopic strain component.

Analogously to the previous case, the determination of the membrane elastic moduli may be obtained by a constrained minimization of the complementary energy, which is a quadratic form on the 72 independent microstress variables of the elements and the three variables $\Sigma_{i j}$ representing the 
homogenized stress. Thanks to the very limited number of optimization variables involved, a standard large scale quadratic programming routine is utilized to solve the elastic problem on the unit cell, varying $E_{b} / E_{m}$ ratio in a wide range and assuming as initial values for the simulations those reported in Table 1.

Results of the simulations are summarized in Figure 9, where the analytic solution by Lourenço (1996) is also reported, to compare with $A_{2} 222$ modulus. Essentially, such approach consists in homogenizing a masonry pillar constituted by two half bricks (height $h$ ) and a joint with thickness $e$. For such a structural system it can be proved that the vertical membrane elastic modulus is $A_{222}=\frac{h+e}{\left(1-\nu_{b}^{2}\right) \frac{h}{E_{b}}+\left(1-\nu_{m}^{2}\right) \frac{e}{E_{m}}}$.

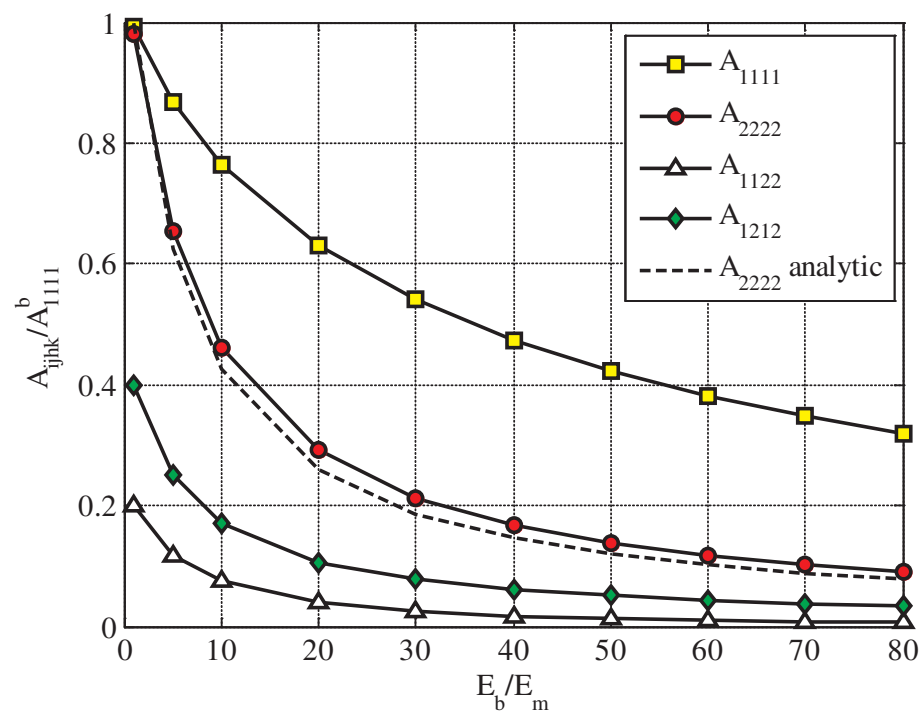

Figure 9. Homogenized in-plane moduli. -a: $A_{1111}$ modulus; -b: $A_{1212}$ modulus; -c: $A_{1122}$ modulus; -d: $A_{2222}$ modulus.

\subsection{Homogenized failure surfaces}

Both stress assumed approaches previously discussed may be extended in the case of materials exhibiting rigid plastic behaviour, infinite ductility and associated flow rules. This is a classic homogenization problem in the rigid plastic case, for which upper and lower bound theorems have been 
provided some decades ago by Suquet (1983) in a general framework. Basing on such theorems, limit analysis combined with homogenization has been extensively applied to masonry structures by e.g. de Buhan and de Felice (1997); Milani et al. (2006a,c); Milani (2011), etc.

De Buhan and de Felice (1997) were the first to apply the kinematic theorem of limit analysis in the framework of masonry homogenization, assuming joints reduced to interfaces with a classic Mohr-Coulomb failure criterion and masonry units infinitely resistant. Milani et al. (2006a,c) and Milani (2011) adopted a static approach, in which either polynomial equilibrated and admissible stress fields were a priori assumed in a finite number of subdomains or a rough discretization with stress constant triangular elements was utilized. In this way, both compressive failure and actual thickness of the joints as well as units crushing may be considered.

These approaches have the following advantages:

1. Masonry homogenized failure surfaces can be recovered making use of well-known linear programming routines and requiring a very limited computational effort;

2. The homogenized failure surfaces so obtained can be implemented in FE limit analysis codes for collapse analysis, without limitations and not requiring to solve a cell problem in each Gauss point at a structural level;

3. They can compete favourably with macroscopic approaches and give relevant information at failure.

On the other hand, some limitations are worth noting:

1. Limit analysis is incapable to give an information on displacements at collapse;

2. As experimental evidences show, frictional behaviour is typically non associated and, at present, mathematical theorems concerning non associated limit analysis applied to homogenization are not available;

3. Masonry behaviour can be quasi-brittle. As a consequence, the assumption of infinite ductility for the constituent materials can be inadequate and preclude the models to be predictive.

Stress assumed approach and polynomial expansion on rectangular sub-domains. The polynomial expansion of the stress field in rectangular sub-domains automatically represents an equilibrated stress field inside the unit cell. To be statically admissible, each point of each subdomain should be subjected to a stress state not violating the material yield. In this framework, the static theorem of limit analysis assures that a point of the failure surface may be found solving the following optimisation 
problem:

$$
\begin{aligned}
& \max \{\hat{\lambda}\} \\
& \text { such that }\left\{\begin{array}{ll}
\hat{\lambda} \mathbf{n}_{\Sigma}=\frac{1}{Y} \sum_{k=1}^{4 k^{\max }} \int_{Y} \widetilde{\mathbf{X}}^{(k)}(\mathbf{y}) \widetilde{\mathbf{S}} \mathrm{d} Y & (a) \\
\mathbf{y} \in Y^{k} & (b) \\
\widetilde{\boldsymbol{\sigma}}=\widetilde{\mathbf{X}}^{(k)}(\mathbf{y}) \widetilde{\mathbf{S}} & (c) \\
\widetilde{\boldsymbol{\sigma}}(\mathbf{y}) \in S^{k} \quad k=1, \ldots, 4 k^{\max } & (d)
\end{array}\right\}
\end{aligned}
$$

where

$-\mathbf{n}_{\Sigma}=\left[\begin{array}{lll}\alpha_{11} & \alpha_{22} & \alpha_{12}\end{array}\right]^{T}$ is a tensor in the homogenized stress space $\Sigma_{11} \quad \Sigma_{22} \quad \Sigma_{12}$

- $\hat{\lambda} \mathbf{n}_{\Sigma}$ represents a macroscopic stress state on the homogenized failure surface $S^{\text {hom }}$, belonging to a straight line from the origin of direction $\mathbf{n}_{\Sigma}$

- $S^{k}$ stands for the failure surface of the component (unit or mortar) belonging to the $i^{\text {th }}$ sub-domain.

- $Y$ is the area of the elementary cell.

The optimisation problem given by Eqs. (12) is generally non-linear as a consequence of the (possible) non-linearity of the strength functions of the components. In addition, condition Eqs. (12) (d) has to be checked in every point of the domain $Y$. Nevertheless, as suggested in a classical paper by Belytschko and Hodge (1970), the check could be avoided imposing the material admissibility only where the stress status is the maximum. This is feasible only for the $P 0$ and $P 1$ models; alternatively, the discretisation proposed here consists in enforcing, in every sub-domain, the admissibility condition in a regular grid of "nodal points" with step $r \times q$ (quasi-lower bound approach).

Within this assumption, the optimisation problem reduces to:

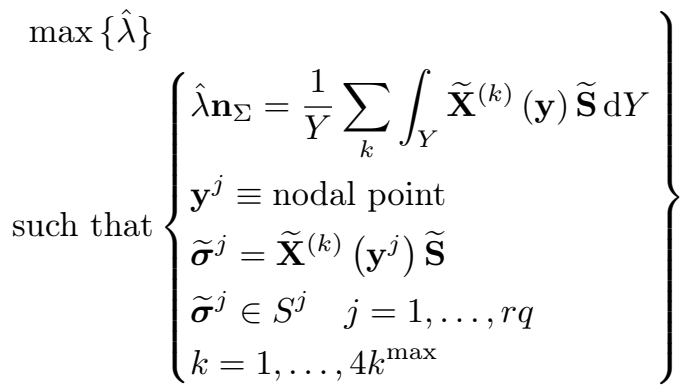


Optimisation problem (13) generally remains non-linear. In order to use linear pro-gramming algorithms, each of the non-linear inequalities of Eqs. (13) could be approximated by a set of linear inequalities (as proposed in the past, for instance, by Anderheggen and Knöpfel (1972) or Olsen (1998), by replacing the yield surfaces with inscribed hyper polyhedrons. Finally, the convergence of the solution obtained should be checked progressively increasing the number of planes of the approximation, see Sloan (1988); Sloan and Kleeman (1995) and Olsen (1998) and many others.

Alternatively and more efficiently, an iterative procedure may be adopted, taking advantage of the fact that the simplex method proceeds from basic solution to basic solution towards an optimal basic solution, i.e. on the vertices of the hyper polyhedron.

The basic idea of the iterative procedure adopted is the following: in the starting step, a coarse linear approximation of the non-linear failure surfaces of the components is adopted, as shown in Figure 10-a. The application of the simplex method in the optimisation at the $i$-th step leads to an optimal solution in a corner of the domain.

From the iterative $i$-th solution point a new tangent plane is added in $P^{\prime}$ as shown in Figure 10-b, so restarting an $(i+1)^{\text {th }}$ optimisation procedure. The iterations continue until a fixed tolerance in the error between the $i^{\text {th }}$ and $(i+1)^{\text {th }}$ solution is reached.

(a)

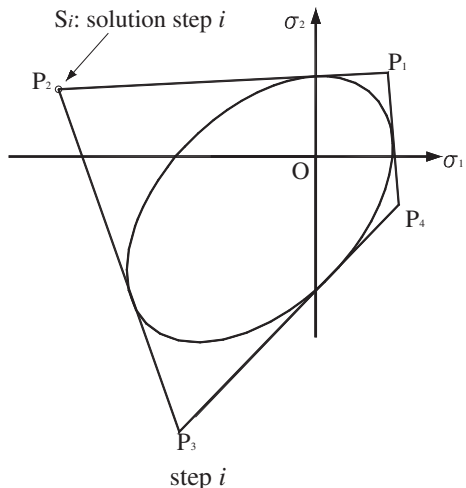

(b)

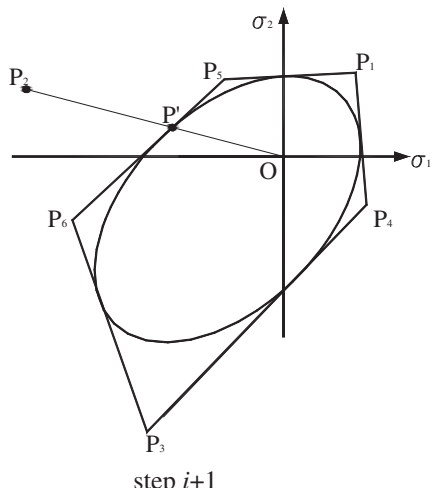

Figure 10. Iterative procedure utilized in the optimization problem.

In Figure 11, the strength domain obtained increasing the degree of the polynomial expansion is represented in the macroscopic stress space with $\Sigma_{12}=0$; the results are compared with a full finite element limit analysis 
on the REV. Mechanical characteristics of the constituent materials are summarized in Table 2; a Mohr-Coulomb failure criterion in plane stress is chosen for mortar joints, while units are supposed infinitely resistant. Units dimensions are $52.5 \times 17.5 \mathrm{~mm}$ (length $\times$ height) and mortar joints are $10 \mathrm{~mm}$ thick.

Table 2. Mechanical properties assumed for mortar joints (plane stress, units infinitely resistant).

\begin{tabular}{|c|c|}
\hline \multicolumn{2}{|c|}{ Mortar } \\
\hline Frictional angle $(\Phi)$ & Cohesion $(c)$ \\
\hline $37^{\circ}$ & $1.0028 \mathrm{MPa}$ \\
\hline$\sigma_{t}=\frac{2 c \cos (\Phi)}{1+\sin (\Phi)}$ & $\sigma_{c}=\frac{2 c \cos (\Phi)}{1-\sin (\Phi)}$ \\
\hline
\end{tabular}

As Figure 11 shows, the model with constant stress tensor $(P 0)$ is unable to reproduce the typical anisotropic behaviour of masonry at failure (Milani et al., 2006a), while the refined models give a progressively increased accuracy of the results (especially $P 3$ and $P 4$ ) in comparison with the FE analysis. Therefore, a cubic interpolation $P 3$ is at least recommended.

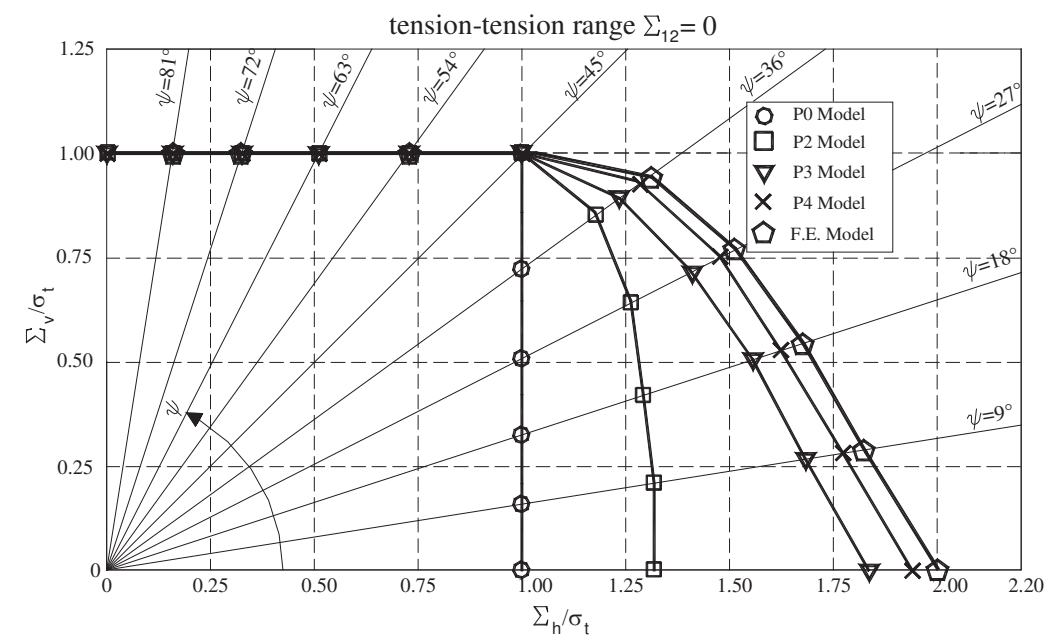

Figure 11. Failure surface in the tension-tension range for the models proposed without shear actions. 
Stress assumed approach and CST elements. When dealing with the discretization of the unit cell by means of CST elements and in presence of finite resistance of both interfaces and triangular elements the homogenization problem may be re-written as:

$$
\begin{aligned}
& \max \lambda \\
& \text { subject to }\left\{\begin{array}{l}
\lambda \alpha=\frac{\sum_{i=1}^{24} \sigma_{x x}^{(i)} A_{i}}{2 a b} \\
\lambda \beta=\frac{\sum_{i=1}^{24} \sigma_{y y}^{(i)} A_{i}}{2 a b} \\
\lambda \gamma=\frac{\sum_{i=1}^{24} \tau^{(i)} A_{i}}{2 a b} \\
\mathbf{A}_{e q}^{I} \mathbf{X}=\mathbf{b}_{e q}^{I} \\
\mathbf{A}_{e q}^{a p} \mathbf{X}=\mathbf{b}_{e q}^{a p} \\
f_{E}^{i}\left(\sigma_{x x}^{(i)}, \sigma_{y y}^{(i)}, \tau^{(i)}\right) \leq 0 \forall i=1, \ldots, 24 \\
f_{I}^{i}\left(\sigma_{I}^{(i)}, \tau_{I}^{(i)}\right) \leq 0 \forall i=1, \ldots, 32
\end{array}\right.
\end{aligned}
$$

where symbols used in equation (14) have the following meaning:

$-\alpha, \beta$ and $\gamma$ indicate the components of the unitary vector $\mathbf{n}_{\Sigma}$, see Figure 12, in the homogenized membrane stress space. The solution of the optimization problem (14) allows the determination of a point on the homogenized failure surface having coordinates $\Sigma_{x x}=\alpha \lambda, \Sigma_{y y}=$ $\beta \lambda$ and $\Sigma_{x y}=\gamma \lambda$. Note that independent variables pass from 75 to 73 introducing the failure multiplier. Usually, masonry in-plane failure surface sections are represented assuming a fixed angle $\vartheta$ between the bed joint and the macroscopic horizontal action $\Sigma_{11}$. Such sections are obtained keeping $\vartheta$ fixed and varying point by point $\psi$ angle, defined as $\psi=\tan ^{-1}\left(\Sigma_{22} / \Sigma_{11}\right)$, where $\Sigma_{22}$ is the macroscopic vertical action. In this framework, vector $\mathbf{n}_{\Sigma}$ has the following form:

$$
\begin{aligned}
& \mathbf{n}_{\Sigma}(1)=\frac{1}{2}(\cos (\psi)(1+\cos (2 \vartheta))+\sin (\psi)(1-\cos (2 \vartheta))) \\
& \mathbf{n}_{\Sigma}(2)=\frac{1}{2}(\cos (\psi)(1-\cos (2 \vartheta))+\sin (\psi)(1+\cos (2 \vartheta))) \\
& \mathbf{n}_{\Sigma}(3)=\frac{1}{2}(\cos (\psi) \cos (2 \vartheta)-\sin (\psi) \cos (2 \vartheta)) \tan (2 \vartheta)
\end{aligned}
$$


- $A_{i}$ is the area of the $i$-ith element $(a b / 8$ or $a b / 16)$;

- $\mathbf{X}$ is a $73 \times 1$ row vector and collects all the optimization unknowns (elements stress components and collapse multiplier);

- $\mathbf{A}_{e q}^{I}=\mathbf{b}_{e q}^{I}$ is a set of linear equations collecting equilibrium constraints on all interfaces. Since 32 interfaces are present in the discretized REV and 2 equality constraints has to be written for each interface (it has to be ensured that both normal and shear stresses are continuous on the interface), $\mathbf{A}_{e q}^{I}$ is a $64 \times 73$ matrix and $\mathbf{b}_{e q}^{I}$ is a $64 \times 1$ vector of all zeros.

- $\mathbf{A}_{e q}^{a p} \mathbf{X}=\mathbf{b}_{e q}^{a p}$ collects anti-periodicity conditions and it is therefore a set of 16 equations. Thus $\mathbf{A}_{e q}^{a p}$ is a $16 \times 73$ matrix and $\mathbf{b}_{e q}^{a p}$ is a $16 \times 1$ vector of all zeros.

$-\mathbf{f}_{E}^{i}\left(\sigma_{x x}^{(i)}, \sigma_{y y}^{(i)}, \tau^{(i)}\right) \leq \mathbf{0}$ is a set of non linear inequalities constraints representing the failure surface adopted for the $i$-th element. Within a linear programming scheme, such failure surfaces are normally linearized. The linearization is usually a lower bound one when a static approach is used, to ensure that a strict lower bound estimation of the collapse load is obtained. Such a lower bound approximation is easily obtained by means of a Delaunay tessellation.

- $\mathbf{f}_{I}^{i}\left(\sigma_{I}^{(i)}, \tau_{I}^{(i)}\right) \leq 0 \forall i=1, \ldots, 32$ plays the role of $\mathbf{f}_{E}^{i}$ for the interfaces. Two typologies of interfaces are present in the model, namely brickbrick interfaces and mortar joints reduce to interfaces. When dealing with the numerical applications reported hereafter, a linearized Lourenço and Rots (1997) failure criterion is adopted for joints reduced to interfaces and a classic Mohr-Coulomb failure criterion is used for brick interfaces. While in the first case a rough approximation of the elliptic cap is assumed (in agreement with Sutcliffe et al. (2001), in the second the constraint is already linear.

- $\sigma_{I}^{(i)}$ and $\tau_{I}^{(i)}$ indicate respectively the normal and shear stress acting on interface $i$.

(14) is a standard linear programming problem and the reader is referred to e.g Anderheggen and Knöpfel (1972) for a critical discussion of efficient (classic) linear programming tools suited for solving (14). On the other hand, it is worth noting that recent trends in limit analysis have demonstrated that the linearization of the strength domain can be circumvented using conic/semidefinite programming (e.g. Krabbenhoft et al. (2005)).

In-plane homogenized failure surfaces. The brickwork considered by Raijmakers and Vermeltfoort (1992) for performing some experimental tests on shear walls is examined. Brick dimensions are $210 \times 52 \times 100 \mathrm{~mm}^{3}$, 


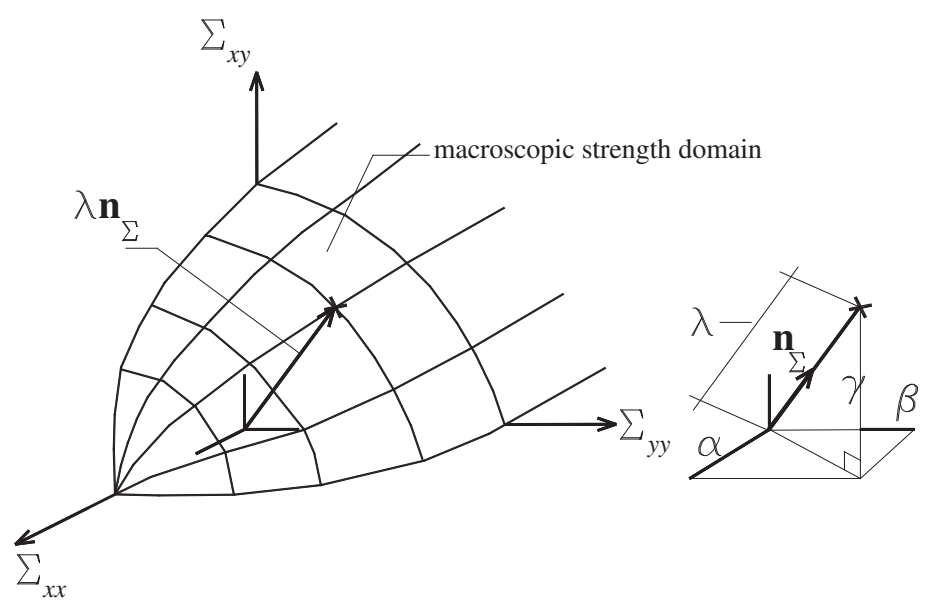

Figure 12. General in-plane load. Meaning of multiplier in the homogenized stress space $\left(\Sigma_{x x}=\mathbf{n}_{\Sigma}(1), \Sigma_{y y}=\mathbf{n}_{\Sigma}(2)\right.$ and $\left.\Sigma_{x y}=\mathbf{n}_{\Sigma}(3)\right)$

whereas the thickness of the mortar joints is $10 \mathrm{~mm}$. Such shear walls have been examined through numerical simulations and a micro-mechanical approach by many authors, e.g. Lourenço and Rots (1997); Milani et al. (2006a); Sutcliffe et al. (2001), etc.

It is worth noting that a comparison with a kinematic formulation is possible for joints reduced to interfaces and bricks infinitely resistant. The kinematic formulation, again solved using linear programming, is the following:

$$
\left.\begin{array}{c}
\chi=\min _{\mathbf{v}} \frac{1}{\Gamma} \int_{\Gamma}[[\mathbf{v}]] \boldsymbol{\sigma} \mathrm{d} s \\
\Sigma^{0}: \mathbf{D}=1 \\
{[[\mathbf{v}]]=\sum_{i=1}^{n} \dot{\lambda}_{i} \nabla_{\boldsymbol{\sigma}} f^{(i)}}
\end{array}\right\}
$$

where $\chi$ is the kinematic limit multiplier of the assigned macroscopic stress $\Sigma^{0}$ and $\dot{\lambda}_{i}$ is the plastic multiplier associated with the (linear) inequality constraint $f^{(i)} \leq 0$ which determines the admissible stress state.

Two models (A and B) for joints are critically examined, see Table (3). They differ only for the compressive cap, which is vertical in model A and with a very prominent shape in model B.

The homogenized surfaces - at different orientations $\vartheta$ of the biaxial load with respect to material axes - in the compression-compression re- 
Table 3. Raijmakers and Vermeltfoort experimental data. Mechanical properties adopted for mortar joints reduced to interfaces and bricks.

\begin{tabular}{|c|c|c|c|}
\hline \multicolumn{4}{|c|}{$\begin{array}{c}\text { Mortar joints reduced to interfaces } \\
\text { (Mohr-Coulomb failure criterion with tension cutoff) } \\
\text { and linearized compressive cap) }\end{array}$} \\
\hline & & Model A & Model B \\
\hline cohesion $[\mathrm{MPa}$ & $c$ & \multicolumn{2}{|c|}{$1.4 f_{t}$} \\
\hline tensile strength [MPa & $f_{t}$ & \multicolumn{2}{|c|}{0.25} \\
\hline compressive strength [MPa & $f_{c}$ & \multicolumn{2}{|c|}{10.5} \\
\hline friction angle [Deg] & $\Phi$ & \multicolumn{2}{|c|}{37} \\
\hline $\begin{array}{l}\text { shape of the linearized compressive } \\
\text { cap [Deg] }\end{array}$ & $\Psi$ & 30 & 90 \\
\hline \multicolumn{4}{|c|}{$\begin{array}{l}\text { Brick interfaces and triangular brick elements } \\
\text { (Mohr-Coulomb failure criterion) }\end{array}$} \\
\hline cohesion [MPa & $c_{b}$ & \multicolumn{2}{|c|}{2} \\
\hline friction angle [Deg] & $F_{b}$ & \multicolumn{2}{|c|}{45} \\
\hline
\end{tabular}

gion obtained using the presented static models (results of both models in practice coincide for polynomial expansions with degrees higher than 5) are reported in Figure 13 (Model A) and Figure 14 (Model B), whereas the homogenized behaviour in the tension-tension region is depicted in Figure 15. In this latter case, obviously Model A and B provide the same result. Along with static failure surfaces, the corresponding kinematic strength domains obtained solving (16) are represented. For graphical convenience, kinematic failure surfaces are slightly shifted. As it can be noted, the agreement between the here revised static approaches and the kinematic procedure is almost perfect for all the points inspected. The results show that the homogenized surface depends on the geometrical and mechanical characteristics assumed for the components. 


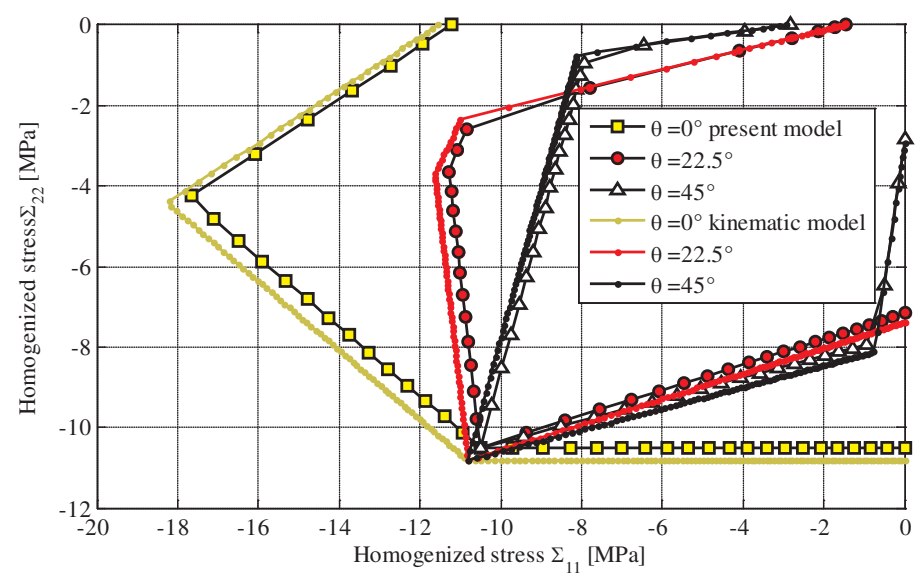

Figure 13. Model A. Compression-compression region. Biaxial strength domain at different orientation of the horizontal action with respect to bed joint direction. Comparison between static approaches and kinematic solution. For graphical convenience, kinematic failure surfaces are slightly shifted from their actual position. 


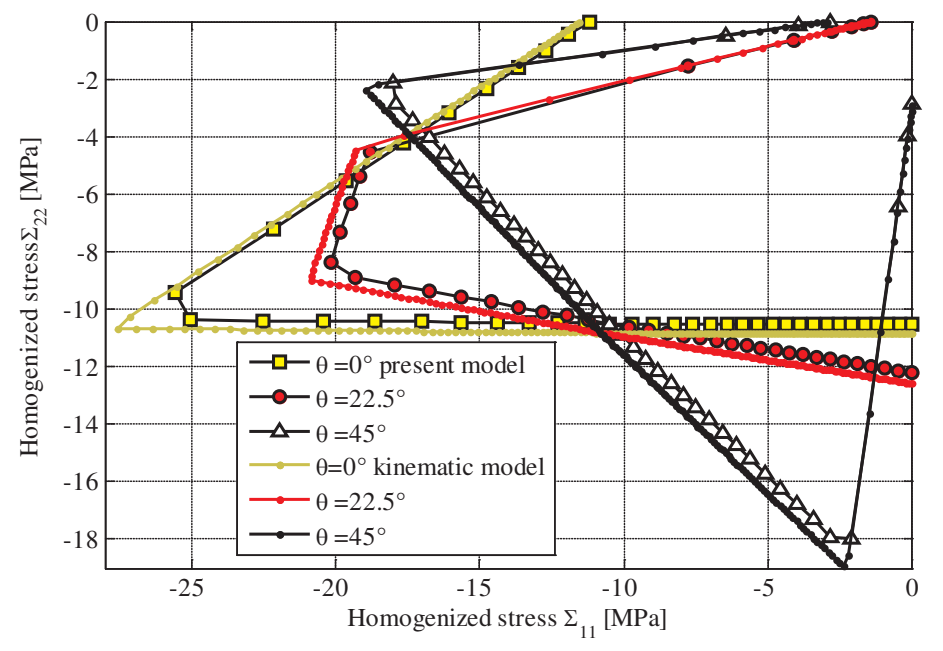

Figure 14. Model B. Compression-compression region. Biaxial strength domain at different orientation of the horizontal action with respect to bed joint direction. Comparison between static approaches and kinematic solution. For graphical convenience, kinematic failure surfaces are slightly shifted from their actual position.

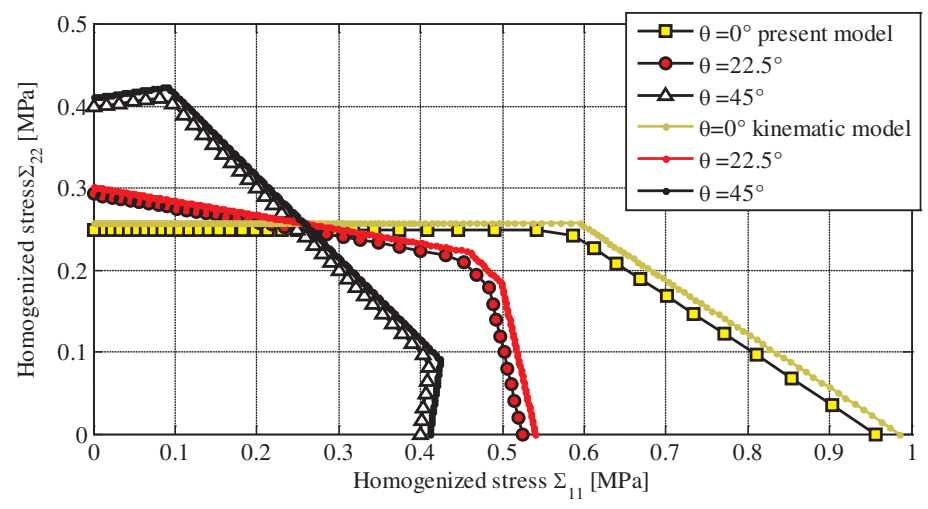

Figure 15. Tension-tension region. Biaxial strength domain at different orientation of the horizontal action with respect to bed joint direction. Comparison between static approaches and kinematic solution. For graphical convenience, kinematic failure surfaces are slightly shifted from their actual position. 
Generalization to the out-of-plane case. The generalization of the second static model, presented in this Chapter, to out-of-plane actions (Kirchhoff-Love hypothesis), if performed within the utilization of standard linear programming routines, requires a subdivision $\left(n_{L}\right)$ of the wall thickness $t$ into several layers (Figure 16-a), with a priori fixed constant thickness $\delta_{L}=t / n_{l}$ for each layer. Hence, to estimate a point of the failure surface in the bending moment-torque space it is necessary to solve the following linear programming problem:

subdivision of masonry thickness in layers

$$
\Delta_{L_{i}}=t / \mathrm{n} \quad \text { layer thickness }
$$

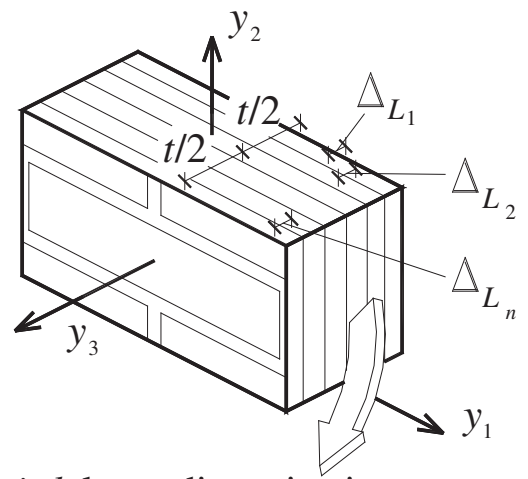

$i$-th layer discretization

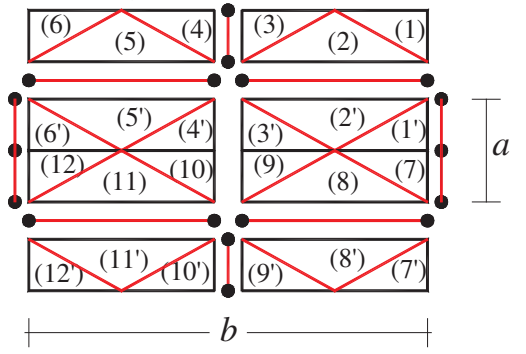

Figure 16. The micro-mechanical model proposed for out-of-plane actions. Subdivision in layers along the thickness and discretization of each layer into triangular equilibrated elements. 


$$
\max \{\lambda\} \quad\left\{\begin{array}{l}
\lambda \alpha=\frac{\sum_{j=1}^{n_{L}} \Delta_{L_{i}}\left(\frac{t+\Delta_{L_{i}}}{2}-j \Delta_{L_{i}}\right) \sum_{i=1}^{24} \sigma_{x x}^{(i, j)} A_{i}}{2 a b} \\
\lambda \beta=\frac{\sum_{j=1}^{n_{L}} \Delta_{L_{i}}\left(\frac{t+\Delta_{L_{i}}}{2}-j \Delta_{L_{i}}\right) \sum_{i=1}^{24} \sigma_{y y}^{(i, j)} A_{i}}{2 a b} \\
\lambda \gamma=\frac{\sum_{j=1}^{n_{L}} \Delta_{L_{i}}\left(\frac{t+\Delta_{L_{i}}}{2}-j \Delta_{L_{i}}\right) \sum_{i=1}^{24} \tau^{(i, j)} A_{i}}{2 a b} \\
N_{x x}=\frac{\sum_{j=1}^{n_{L}} \Delta_{L_{i}} \sum_{i=1}^{24} \sigma_{x x}^{(i, j)} A_{i}}{2 a b}=\Sigma_{x x} t=0 \\
N_{y y}=\frac{\sum_{j=1}^{n_{L}} \Delta_{L_{i}} \sum_{i=1}^{24} \sigma_{y y}^{(i, j)} A_{i}}{2 a b}=\Sigma_{y y} t=0 \\
N_{x y}=\frac{\sum_{j=1}^{n_{L}} \Delta_{L_{i}} \sum_{i=1}^{24} \tau^{(i, j)} A_{i}}{2 a b}=\Sigma_{x y} t=0 \\
\mathbf{A}_{e q}^{I} \mathbf{X}=\mathbf{b}_{e q}^{I} \quad \\
\mathbf{A}_{e q}^{a p} \mathbf{X}=\mathbf{b}_{e q}^{a p} \\
f_{E}^{i, j}\left(\sigma_{x x}^{(i, j)}, \sigma_{y y}^{(i, j)}, \tau^{(i, j)}\right) \leq 0 \forall i=1, \ldots, 24 \forall j=1, \ldots, n_{L} \\
f_{I}^{i, j}\left(\sigma_{I}^{(i, j)}, \tau_{I}^{(i, j)}\right) \leq 0 \forall i=1, \ldots, 32 \forall j=1, \ldots, n_{L}
\end{array}\right.
$$

where all the symbols have been already introduced for the in-plane case.

With respect to the in-plane case, the following key issues are worth noting:

- $\lambda$ is the value of the failure strength in the $M_{x x}-M_{y y}-M_{x y}$ space;

$-\alpha, \beta$ and $\gamma$ indicate the components of the unitary vector $\mathbf{n}_{\Sigma}$, see Figure 12, in the homogenized $M_{x x}-M_{y y}-M_{x y}$ space, in analogy to what stated for the in-plane case;

- $\mathbf{A}_{e q}^{I} \mathbf{X}=\mathbf{b}_{e q}^{I}$ collects equilibrium constraints of all interfaces of each layer. Since between contiguous layers no shear stresses are exchanged, such constraints are the same of the in-plane case, one set written for each layer. $\mathbf{A}_{e q}^{I}$ is a $64 n_{L} \times\left(72 n_{L}+1\right)$ matrix and $\mathbf{b}_{e q}^{I}$ is a $64 n_{L} \times 1$ 
vector of all zeros. Analogous considerations can be repeated for the equations set $\mathbf{A}_{e q}^{a p} \mathbf{X}=\mathbf{b}_{e q}^{a p}$, which collects anti-periodicity conditions for each layer. For the out-of-plane case, $\mathbf{A}_{e q}^{a p}$ is a $16 n_{L} \times\left(72 n_{L}+1\right)$ matrix and $\mathbf{b}_{e q}^{a p}$ is a $16 n_{L} \times 1$ vector of all zeros;

- differently to the in-plane case, three additional equality constraints have to be imposed, corresponding to require that homogenized membrane actions $N_{x x}-N_{y y}-N_{x y}$ are equal to zero; - vector $\mathbf{X}$ collects all the unknown stresses of each $\mathrm{FE}$ of each layer). Therefore, $\mathbf{X}$ is a vector of length $3 \times 24 \times n_{L}$.

Finally, it is worth noting that membrane actions are kept, for the sake of simplicity, constant and independent from load multiplier. Consequently, in-plane actions effect optimization only in the evaluation of $M_{x x}, M_{y y}, M_{x y}$ strength domains. Generally, this assumption is technically acceptable for experimental tests where vertical pre compression $N_{y y}$ is constant and applied before out-of-plane actions.

\subsection{Out-of-plane homogenized failure surfaces}

In the first example, the ultimate masonry horizontal bending, torsion and vertical bending (i.e. $M_{x x}, M_{x y}$ and $M_{y y}$ ) are evaluated in absence of pre-compression.

Table 4. Mechanical properties adopted for the out-of-plane numerical simulations in absence of vertical pre-compression (UNI bricks).

\begin{tabular}{|l|c|c|}
\hline \multicolumn{3}{|c|}{$\begin{array}{c}\text { Mortar joints reduced to interfaces } \\
\text { (Mohr-Coulomb failure criterion) }\end{array}$} \\
\hline friction angle [Deg] & $\Phi$ & 27 \\
\hline cohesion [MPa ] & $c$ & 0.132 \\
\hline
\end{tabular}

Standard Italian UNI bricks of dimensions $55 \times 120 \times 250 \mathrm{~mm}^{3}$ (height $\times$ thickness $\times$ length) and mortar joints reduced to interfaces with a Classic Mohr-coulomb failure criterion are considered. The same simulations have been performed in Cecchi et al. (2007) using a kinematic approach. Mechanical characteristics adopted for joints are summarized in Table 4.

In Figure 17 and Figure 18 respectively, sections $M_{x x}-M_{y y}$ and $M_{x x}-$ $M_{x y}$ of the macroscopic failure surface are reported, at 4 increasing values of $n_{L}$, compared with Cecchi et al. (2007) results. The resultant failure surfaces well approximate the upper bound reference surface for $n_{L}>10$. hence very coarse discretizations along the thickness may be used. Results show again a dependence on the geometrical and mechanical characteristics assumed for the components. 


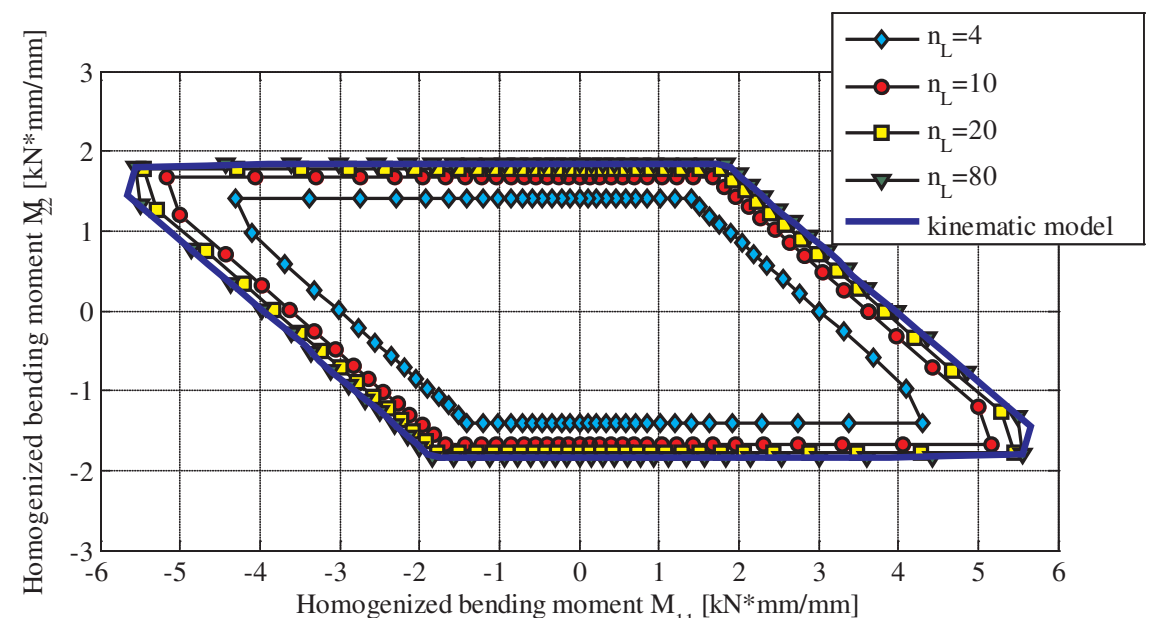

Figure 17. $M_{x x}-M_{y y}$ Failure surface obtained at increasing refinement of the subdivision along the thickness.

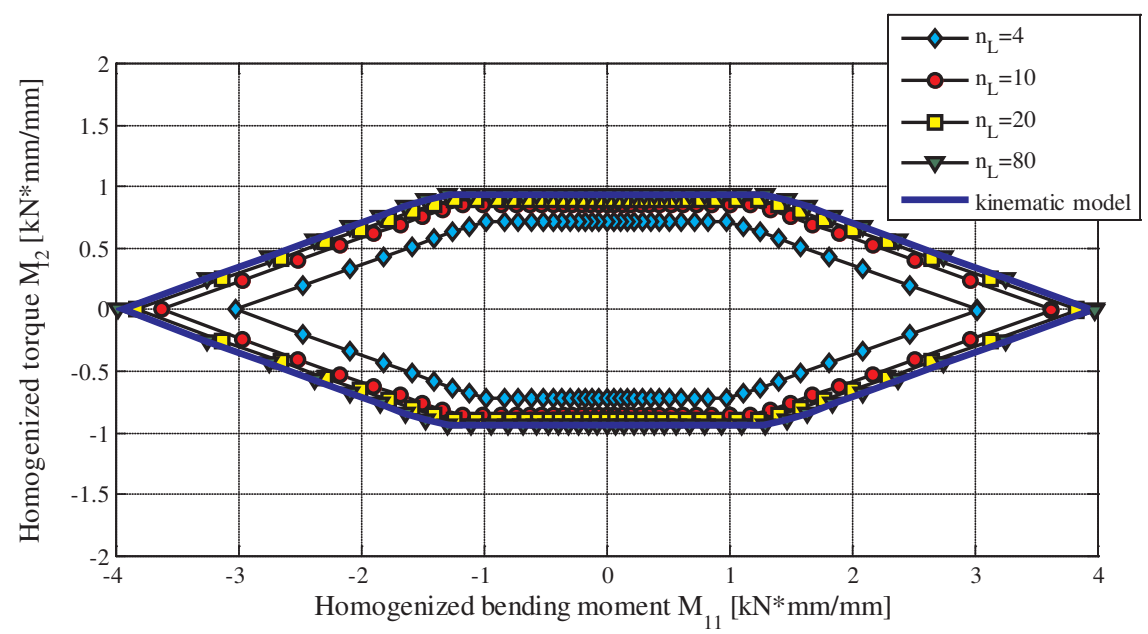

Figure 18. $M_{x x}-M_{x y}$ Failure surface obtained at increasing refinement of the subdivision along the thickness. 


\section{Structural Level}

The homogenized failure surface obtained with the above approaches may be easily coupled with finite element limit analysis codes. Both upper and lower bound approaches have been developed, for in- and out-of-plane loaded masonry walls (Milani et al., 2006b,c) with the aim of providing a full set of numerical data for the design and/or the structural assessment of complex structures. For in-plane loads, the finite element lower bound analysis is based on the equilibrated triangular element bySloan (1988), while the upper bound is based on a modified version of the triangular element with discontinuities of the velocity field in the interfaces by Sloan and Kleeman (1995). The modification takes into account the actual shape of the yield surface for the homogenized material in the interfaces.

When dealing with out-of-plane loads, the triangular plate bending element proposed independently by Hellan (1967) and Herrmann (1967) has been adopted for lower bound calculations, whereas the triangular element proposed by Munro and da Fonseca (1978) has been implemented and employed for the upper bound analyses.

\subsection{In-plane loads: shear wall with central opening}

The first structural example discussed consists on a windowed masonry shear wall. A set of experimental tests are available from Raijmakers and Vermeltfoort (1992). Two series were tested, corresponding to specimens with and without openings. Here only windowed panels are considered for the sake of conciseness. Two identical walls were tested, labeled as J2G and J3G. The width/height ratio $(\mathrm{L} / \mathrm{H})$ of the shear walls is 990/1000 $([\mathrm{mm}] /[\mathrm{mm}])$; the panels were built up with 18 courses of bricks, from which 16 courses were active and 2 were clamped in stiff steel beams, Figure 19. Brick dimensions are $210 \times 52 \times 100 \mathrm{~mm}^{3}$ and the mortar joints are $10 \mathrm{~mm}$ thick. A vertical pre-compression of $0.3 \mathrm{~N} / \mathrm{mm}^{2}$ was applied on the top and its resultant was kept constant during the complete loading procedure. The stiff steel beam did not allow rotations of the top and was subsequently pushed with an increasing horizontal force.

The central opening defines two small relatively weak piers and forces the compressive strut that develops under horizontal loading to spread around both sides of the opening. The experimental crack pattern as reported by Raijmakers and Vermeltfoort is illustrated in Figure 19-a.

For the numerical analysis, a homogenized mesh constituted by 448 elements is utilized. Mechanical properties assumed for the constituent materials are summarized in Table 3 and are taken in agreement with both experimental data provided by Raijmakers and Vermeltfoort (where avail- 


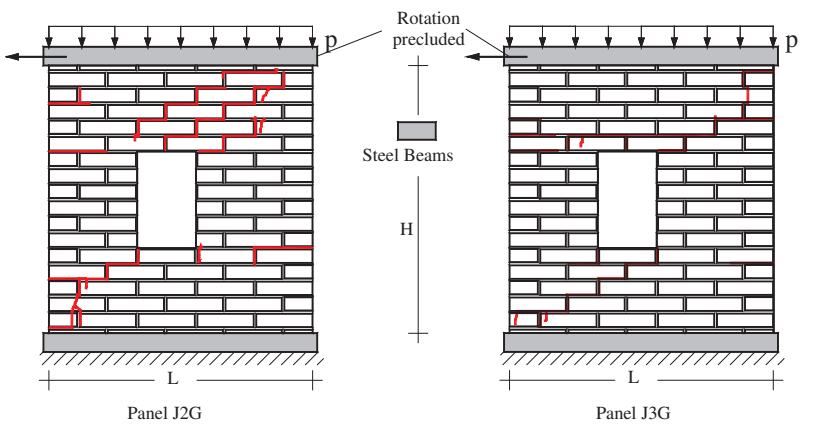

Figure 19. Windowed masonry shear wall by Raijmakers and Vermeltfoort.

able) and Lourenço (1996), where the same numerical analyses have been presented within a heterogeneous approach.

In Figure 20, a comparison among collapse load provided by the homogenized limit analysis model proposed in Milani (2011) and here recalled, the heterogeneous approach by Lourenço (1996) and experimental load-displacement curves (2 replicates) is presented. Furthermore, Figure 21 illustrates the limit analysis resultant deformed shape at failure (upper bound solution) and the map of normalized plastic dissipation (representing damage in the framework of limit analysis).

As it is possible to notice, the response provided by limit analysis seems in good agreement with existing literature, both in terms of collapse load predictions and crack pattern.

\subsection{Out-of-plane loads: windowed panel in two-way bending}

An out-of-plane validation of the homogenization models presented previously is available in Milani et al. (2006c) and Milani (2011).

The panels re-analyzed here consist of solid clay brick masonry. The tests were carried out by Chong et al. (1994) and are denoted by SB. Four different configurations were tested, built in stretcher bond between two stiff abutments with the vertical edges simply supported (allowance for in-plane displacements was provided) and the top edge free. A completely restrained support was provided at the base because of practical difficulties in providing a simple support. The panels were loaded by air-bags until failure with increasing out-of-plane uniform pressure $p$. The reader is referred to Milani et al. (2006c) for a detailed description of geometric dimensions, loads application, structural FE implementation and discussion of results.

Figure 22 shows typical comparisons between experimental pressure- 


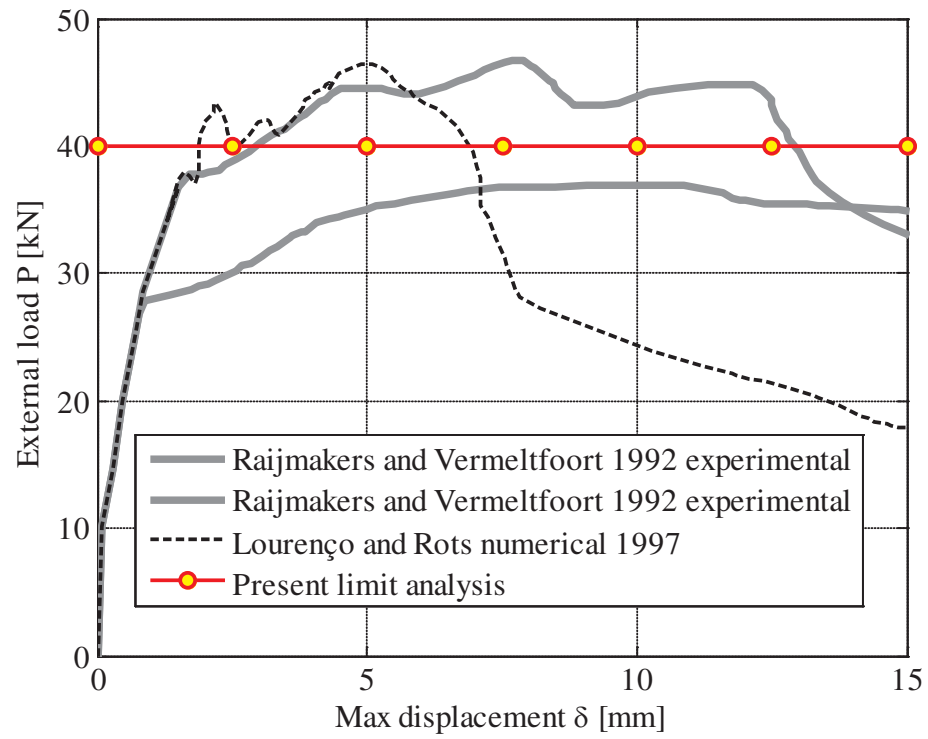

Figure 20. Windowed masonry shear wall by Raijmakers and Vermeltfoort. Comparison among collapse load provided by homogenized limit analysis, a numerical heterogeneous approach and experimental load-displacement curves.
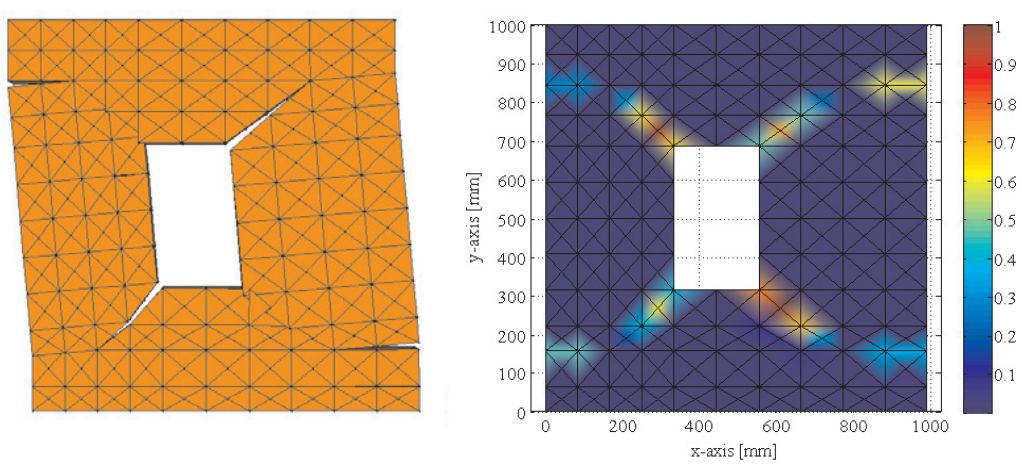

Figure 21. Windowed masonry shear wall by Raijmakers and Vermeltfoort. Left: deformed shape at collapse. Right: normalized plastic dissipation patch. 
displacement curves by Chong et al. (1994), numerical pressure displacement curves obtained by means of an orthotropic elasto-plastic macro-model (Lourenço, 2000) and the homogenized limit analysis results (Milani et al., 2006c). In addition, Figure 23 shows typical results of the numerical analysis in terms of principal moment distribution and mechanisms at failure. The agreement with experimental results is worth noting in all cases analysed.
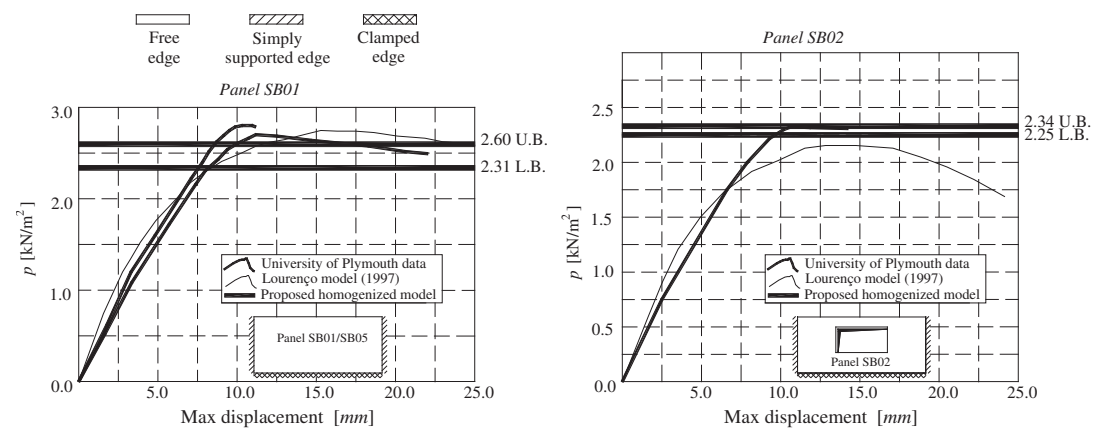

Figure 22. Stress field polynomial expansion approach (out-of-plane model). Comparison between experimental and numerical results obtained, University of Plymouth experimental tests
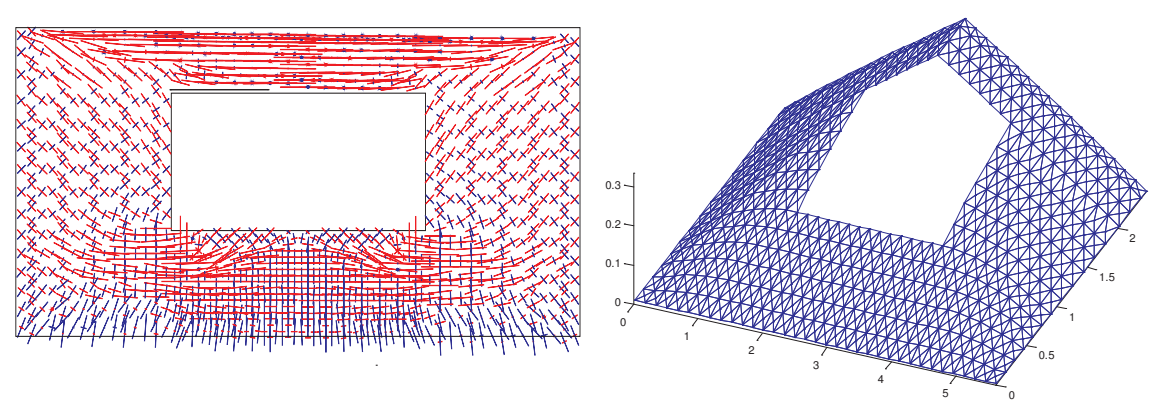

Figure 23. Typical numerical results (Panel SB02) obtained by means of the stress field polynomial expansion approach (out-of-plane model). (a) lower bound results (principal moments at collapse); (b) upper bound results (deformed mesh at collapse). 


\section{Dynamics and Seismic Behaviour}

The seismic response of buildings is particularly difficult to characterize due to its nature, the low number of strong events in a given location, the site effects, the attenuation laws, the non-linear response of the structure, the relevance of execution defects, and many other factors. The seismic action is usually defined in codes via elastic response spectra, which are graphical representations of the maximum value of the response for a single-degreeof-freedom system as a function of the period. From the elastic response spectrum synthetic accelerograms can be generated, which provide the time history of accelerations at the foundations. Recorded accelerograms from real earthquakes also exist, being their most relevant characteristics the amplitude, the frequency contents and the duration.

In case of seismic loading on unreinforced masonry buildings, it is certain that non-linear behaviour is triggered at early stages of loading and linear elastic analysis is not an option. Alternative options seem to be push-over methods, as recommended in most codes for earthquake safety assessment, or non-linear time integration methods, which provide complex and time consuming tools hardly available for practitioners. Another much relevant property in case of seismic loading is the presence of floors that provide diaphragmatic action and the so-called "box-behaviour". This possible feature is not usually present in ancient masonry buildings while being present in modern unreinforced masonry buildings, requiring different models of analysis, as addressed next.

\subsection{Masonry structures with box behaviour}

Modern masonry buildings usually adopt solutions for the slabs that provide considerable in-plane stiffness. This is done by using monolithic solutions for the floors, in concrete and steel, and also by establishing an effective connection between slabs and walls. Moreover, many existing buildings originally constructed with timber floors are capable of providing some diaphragmatic action or have been rehabilitated by stiffening the floors and by providing adequate connections.

The effect of floor diaphragms combined with the in-plane response of structural walls provides box behaviour to the buildings, which usually leads to good performance when subjected to earthquakes. The first assessment method for seismic analysis of masonry buildings was developed under this simple hypothesis. As result of research studies in former Yugoslavia and the 1976 Friuli earthquake, the POR method was introduced in the Italian region of Friuli-Venezia Giulia, to assess the seismic performance of existing masonry buildings, see Marques and Lourenço (2011). Despite its simplicity, 
this method was used until very recently in the analysis of existing buildings and in the design of new buildings, in Italy. Its limitations, namely the consideration of an independent storey mechanism, and the 2002 Molise earthquake, clearly stressed the need of methods that consider the overall response of the masonry structures.

Modern regulations, namely Eurocode 8 (CEN, 2004), seriously penalize structural masonry with a low behaviour factor that renders unreinforced masonry impossible, in opposition with experimental findings. Methods inspired in the POR method and based on macro-elements have been developed, particularly in Italy, e.g. Gambarotta and Lagomarsino (1996) and Magenes and Fontana (1998). These methods seem the most appropriate for design and assessment of masonry buildings, given their widespread in commercial software, the simplicity of modelling, the straightforward interpretation of results and the accuracy demonstrated in different validations. The methods are incorporated in the 3Muri [www.stadata.com] and ANDILWall/SAM II [www.crsoft.it/andilwall] computer codes, respectively. While 3Muri formulation is based on the kinematic equilibrium of the macro-elements according to the panel degrees of freedom, SAM II creates an equivalent frame idealization for a global analysis.

The 3Muri and SAM II computer codes perform the safety verification by a nonlinear static (pushover) analysis that simulates the evolution of the structural condition during the earthquake, through application of incremental horizontal forces until collapse. The behaviour of the structure is represented by the so-called "capacity curve", which represents the value of the base shear versus the displacement of a control point (usually the mass centroid of the roof slab). In Marques and Lourenço (2011), a benchmark analysis was carried out demonstrating good agreement of the results for a pushover analysis on two buildings.

To demonstrate the possibilities of construction with unreinforced masonry and the inadequacy of European codes, the seismic safety of buildings with one up to three storeys, based on a pushover analysis carried out in the 3Muri computer code, is considered next. The building configurations studied are shown in Figure 24, namely a one-storey module, and two- and three-storey buildings for semi-detached houses.

Figure 25 illustrates the ultimate response in terms of deformed configuration and damage of the three buildings, where it can be observed that the collapse mechanisms are essentially induced by flexure, while plastic mechanisms by shear are only found for the three-storey building in spandrels adjacent to the first slab.

Based on the requirements for earthquake resistance imposed by the Italian code OPCM 3431 (2005), and assuming the seismic parameters de- 


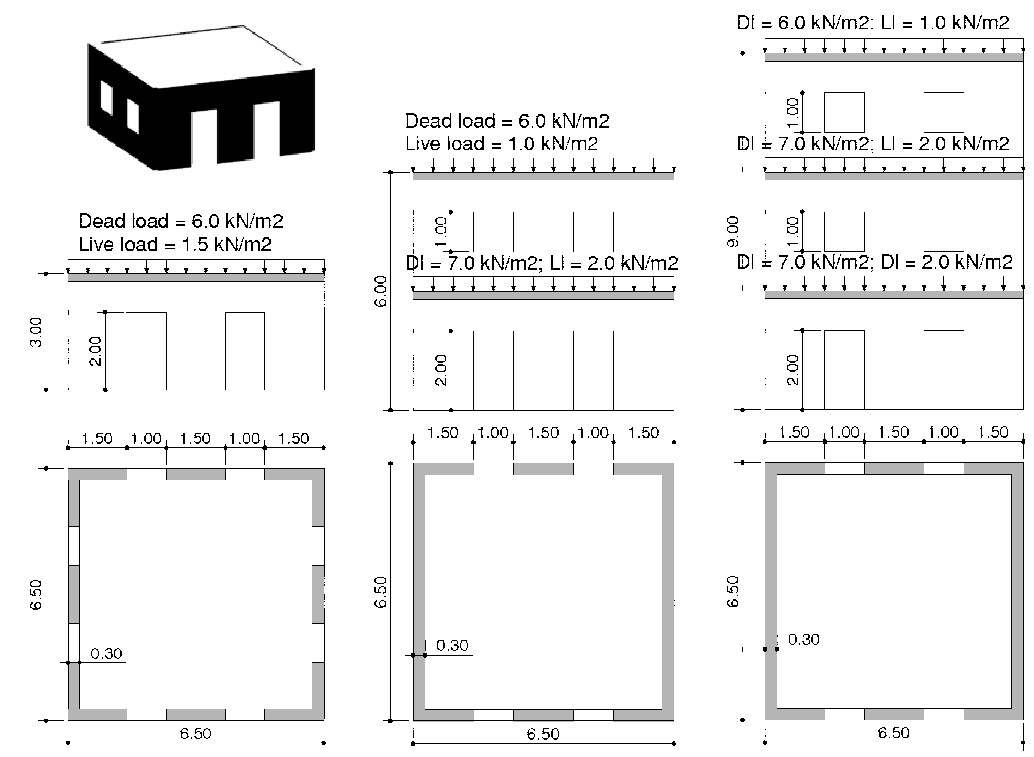

Figure 24. Building configurations studied.

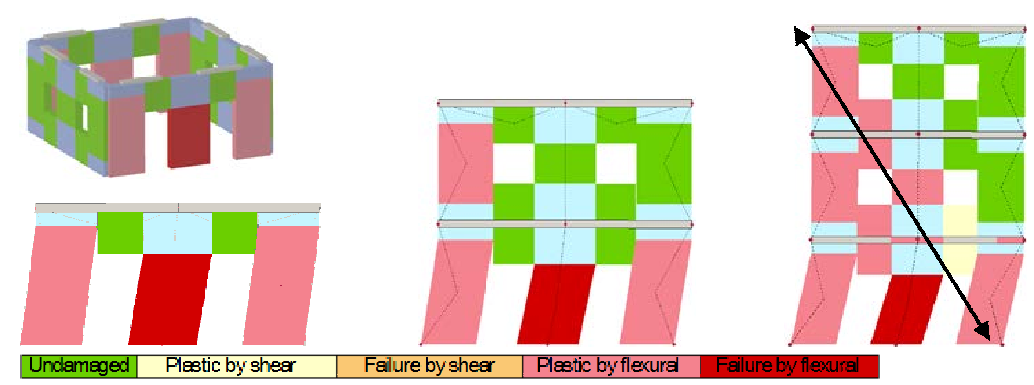

Figure 25. Assessment of ultimate damage and deformed configurations. 
fined in the Portuguese Annex to Eurocode 8 (CEN, 2004), the possibility to construct the studied buildings in Portugal was evaluated using 3Muri, see Figure 26. Performing an elastic analysis adopting a behaviour factor of 1.5, as recommended by Eurocode 8, provides a safety over conservative assessment, as shown in Figure 27a. A better correspondence between the pushover and linear analysis is achieved by assuming the behaviour factor values proposed by OPCM 3431, as shown in Figure 27b. In the case of the regular building configuration adopted, behaviour factors of 4.0, 3.0 and 3.5 , respectively for the one-to-three storey buildings allow a good match between the linear and nonlinear analysis. This example clearly demonstrates the need of adopting adequate analysis techniques for the seismic assessment of unreinforced masonry structures.

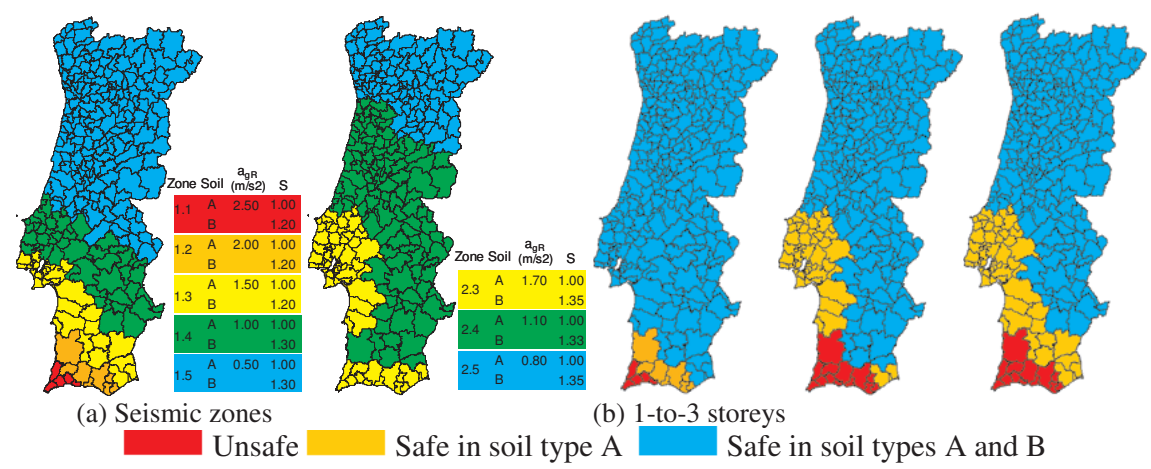

Figure 26. Safety mapping in Portuguese seismic zones by a pushover analysis.

\subsection{Masonry structures without box behaviour}

Differently from the structures considered in the previous section, unreinforced masonry structures without box behaviour have shown poor performance in many past earthquakes. The reasons for the poor performance are the inherent brittleness, lack of tensile strength, lack of ductility, flexible floor diaphragms and lack of connection between the structural elements. Next, illustrative examples of different analysis tools for the seismic analysis of these structures are presented, see (Lourenço et al., 2011) for additional details.

The first example is the S. Torcato church in Portugal, where limit analysis using macro-blocks was carried out for the seismic performance assessment, as the church exhibits significant damage and requires strengthening. 


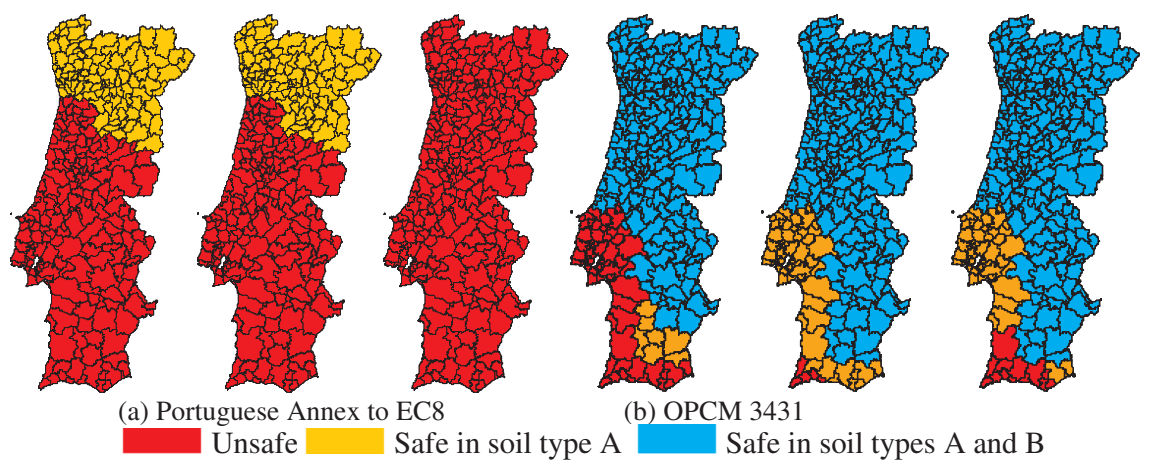

Figure 27. Safety mapping in Portuguese seismic zones by a linear elastic analysis.

In existing masonry buildings partial collapses often occur due to seismic action, generally, with the loss of equilibrium of rigid bodies. In this case study, four mechanisms were defined, based on the inspection and structural analysis of the structure. The mechanisms were partially marked by existing cracks. Figure 28 shows the mechanisms considered in the limit kinematic analysis. According to the limit analysis, the church is safe and the lowest safety factor is equal to 1.69 (with overturning of the tympanum).

This analysis method is conceptually simple and an abacus of possible mechanisms is available at MIBAC 2007 (2007). In the present case, the method is easy to apply as the collapse mechanisms are also partially defined by existing cracking. It is believed that the benefits of using collapse mechanism analysis are the following: (a) the method is intuitive and does not requires advanced knowledge of physics or mechanics, being therefore at reach of most practitioners; (b) the abacus of possible collapse mechanisms and the observation of previous collapses under earthquake action provide are the basis of the inductive approach; (c) the method is conceptually and analytically correct, if the proper collapse mechanisms are selected. It is believed also the method possesses a strong drawback: if wrong collapse mechanisms are selected, the seismic assessment (and related strengthening measures, if applicable) is meaningless. Therefore, practitioners must ensure correct selection of collapse mechanism, either by a detailed inspection of the structure being studied or by adopting more sophisticated analysis methods. This is certainly the case of complex or unusual structures, for which the mechanisms might not be obvious. Another example would be to use pushover analysis or time integration analysis to get more confidence on 


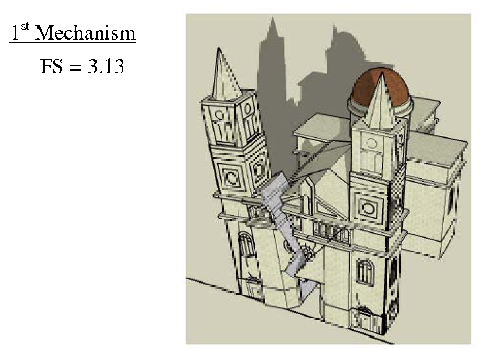

(a)

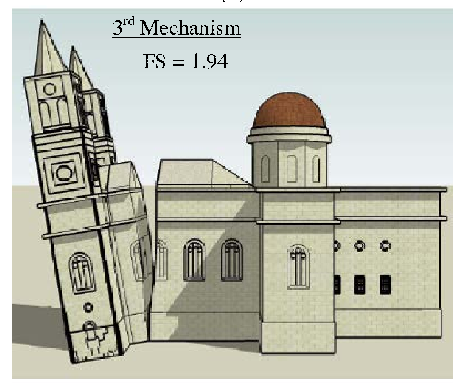

(c)

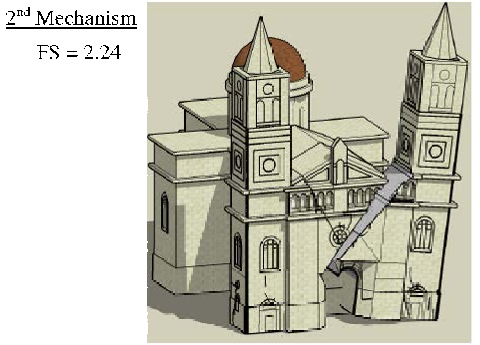

(b)

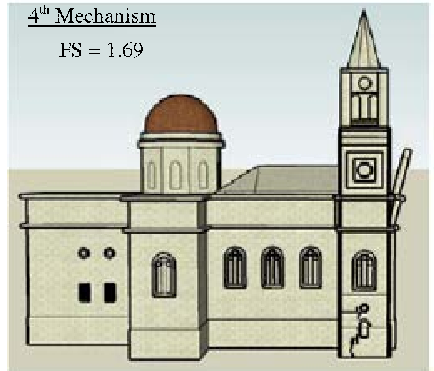

(d)

Figure 28. Possible collapse mechanisms: (a) overturning of the left tower; (b) overturning of the right tower; (c) overturning of the façade; (d) overturning of the tympanum. (FS is the safety factor).

collapse mechanisms and then adopt the correct collapse mechanism analysis to calculate the required strengthening.

A second example of application is the Qutb Minar, in New Deli, India. To evaluate its seismic performance different techniques of structural analyses were used, namely non-linear dynamic analysis and non-linear static analysis (pushover analysis). In the analyses different numerical models were considered. Two models were prepared using the Finite Element Method (FEM), both are three-dimensional models but one uses 3D solid elements (Solid Model) while the other one was performed with 3D composite beams (Beam Model). A simplified in-plane model of the minaret based on the Rigid Element Method was also developed. The Rigid Element Method idealizes the masonry structure as a mechanism made of rigid elements and springs (Casolo and Peña, 2007). The numerical models were updated from dynamic identification tests.

In the FEM models, the physical non-linear behaviour of the masonry was simulated using the Total Strain Crack Model detailed in DIANA 
(2005), with non-linear behaviour given by a parabolic law in compression and an exponential law in tension (fixed crack model with variable shear retention). In the rigid body and spring model (RBSM), the constitutive law for axial springs is parabolic in compression and bi-linear in tension with softening. A Mohr-Coulomb law was considered for shear springs in order to relate the shear stresses with the axial stresses.

The dynamic analyses were carried out using five artificial accelerograms compatible with the elastic response spectrum for Delhi $(\mathrm{PGA}=0.20 \mathrm{~g}$ ). Pushover analyses were carried out considering a uniform acceleration distribution. The load was applied with increasing acceleration in the horizontal direction and a control point at the top of the tower was considered. Figure 29a shows the capacity curves (lateral displacement - seismic coefficient at the base level). Similar behaviour was found with the different models. It can be observed that the average seismic factor is 0.20 and the minaret collapses by overturning at the base.

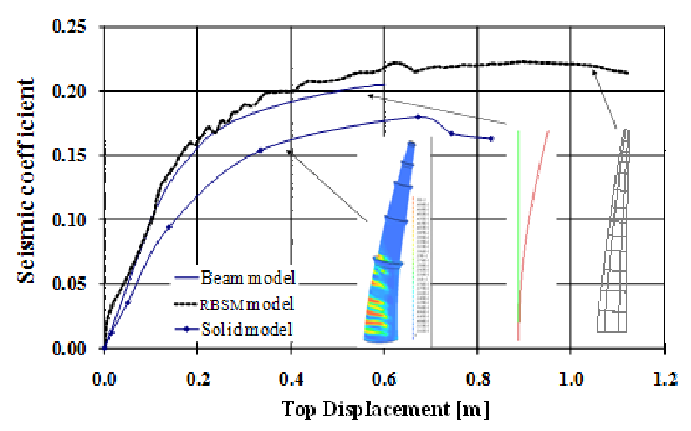

(a)

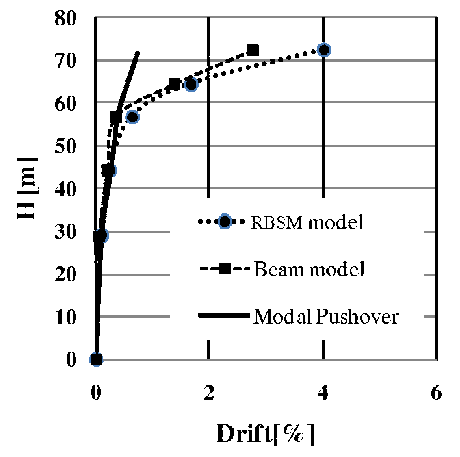

(b)

Figure 29. Results of the pushover analyses: (a) capacity curves of the pushover analyses proportional to the mass; (b) comparison between the drifts obtained through modal pushover analysis and trough dynamic analyses of the Beam and RBSM Models.

In order to study the influence of the distribution of the lateral load in the pushover analysis, additional non-linear static analyses were performed. Four different configurations of lateral loads were considered: (a) linear distribution of the displacement along the height; (b) loads proportional to the first modal shape; (c) adaptive pushover analysis, changing the load distribution according to the changes in the first modal shape during the analysis; (d) modal pushover analysis (Chintanapakdee and Chopra, 2003). 
The results of the pushover analyses, namely the failure mode and displacements' distribution along the height, are not in agreement with the non-linear dynamic analysis. Even modal pushover analysis, in which the responses of the first seven modes were combined, is not able to simulate the amplification of the response at higher levels (Figure 29b). This example demonstrates again the need of adopting adequate analysis techniques for the seismic assessment of unreinforced masonry structures.

\section{Conclusions}

Constraints to be considered in the use of advanced modelling are the cost, the need of an experienced user/engineer, the level of accuracy required, the availability of input data, the need for validation and the use of the results.

As a rule, advanced modelling is a necessary means for understanding the behaviour and damage of (complex) historical masonry constructions and examples have been addressed here. For this purpose, it is necessary to have reliable information on material data, and recommendations are provided in this chapter.

Micro-modelling techniques for masonry structures allow a deep understanding of the mechanical phenomena involved. For large scale applications, macro-block approaches or average continuum mechanics must be adopted and homogenization techniques represent a popular and active field in masonry research. Homogenization techniques represent a popular and active field in masonry research. Several approaches have been recently introduced by different authors and a first attempt to catalogue them and to discuss pros and cons are carried out in this Chapter. Even if it impossible to predict the future of masonry research, this Chapter addresses in detail two different static approaches considered particularly relevant. The first approach is based on a polynomial expansion of the stress field coupled with limit finite elements analysis, whereas the second relies into a discretization of the unit cell by means of a few constant stress finite elements (CST) with joints reduced to interfaces.

Finally, the possibilities of assessment unreinforced masonry structures subjected to seismic loading is addressed using different techniques. It is advocated that linear elastic analysis can hardly be used, as masonry features low tensile strength, and different models must be used in the presence or absence of adequately connected floors, the so-called box behaviour.

In case of box behaviour the available methods have been briefly reviewed. Their performance is good and the knowledge is sound, with some corrections needed in the recent European regulations (Eurocode 8). When box behaviour cannot be guaranteed, the analysis of masonry structures 
becomes rather complex. The use of macro-models and limit analysis seems the current trend but difficulties arise in the practical use, namely with respect to validation of the hypothesis of the user and the risk of selecting inadequate failure mechanisms. The non-linear static analysis could be a good and easily understood approach, because it is based on the simple evaluation of the requested deformation with respect to the displacement capacity of the building. This approach is in agreement with the modern provisions for structural assessment. Still, the results obtained from the non-linear static and dynamic analyses indicate quite different response of these structures to earthquakes. It is therefore concluded that non-linear pushover analysis does not simulate correctly the failure mode of masonry structures without box behaviour, even if higher modes are considered via modal pushover analysis.

\section{Bibliography}

E. Anderheggen and H. Knöpfel. Finite element limit analysis using linear programming. International Journal of Solids and Structures, 8(12): 1413-1431, 1972.

A. Anthoine. Derivation of the in-plane elastic characteristics of masonry through homogenization theory. International Journal of Solids and Structures, 32(2):137-163, 1995.

A. Anthoine. Homogenization of periodic masonry: plane stress, generalized plane strain or 3d modelling? Communications in numerical methods in engineering, 13(5):319-326, 1997.

T. Belytschko and P.G. Hodge. Plane stress limit analysis by finite elements. Journal of the Engineering Mechanics Division, 96(6):931-944, 1970.

D. Caillerie. Thin elastic and periodic plates. Mathematical Methods in the Applied Sciences, 6(1):159-191, 1984.

S. Casolo and F. Peña. Rigid element model for in-plane dynamics of masonry walls considering hysteretic behaviour and damage. Earthquake engineering \& structural dynamics, 36(8):1029-1048, 2007.

CEB-FIP. Model Code 90. Thomas Telford Ltd., UK, 1993.

A. Cecchi and K. Sab. A multi-parameter homogenization study for modelling elastic masonry. European Journal of Mechanics-A/Solids, 21(2): 249-268, 2002.

A. Cecchi, G. Milani, and A. Tralli. Validation of analytical multiparameter homogenization models for out-of-plane loaded masonry walls by means of the finite element method. Journal of engineering mechanics, 131(2): 185-198, 2005. 
A. Cecchi, G. Milani, and A. Tralli. A Reissner-Mindlin limit analysis model for out-of-plane loaded running bond masonry walls. International journal of solids and structures, 44(5):1438-1460, 2007.

CEN. Eurocode 8: Design of structures for earthquake resistance, Part 1: General rules, seismic action and rules for buildings. European Committee for Standardization, Belgium, 2004.

CEN. Eurocode 6: Design of masonry structures, Part 1-1: General rules for reinforced and unreinforced masonry structures. European Committee for Standardization, Belgium, 2005.

C. Chintanapakdee and A.K. Chopra. Evaluation of modal pushover analysis using generic frames. Earthquake engineering $\& 3$ structural dynamics, 32(3):417-442, 2003.

V.L. Chong, C. Southcombe, and I.M. May. The behaviour of laterally loaded masonry panels with openings. In 3th Int. Masonry Conf. Proc. Brit. Mas. Soc., pages 178-182, London, 1994.

P. de Buhan and G. de Felice. A homogenization approach to the ultimate strength of brick masonry. Journal of the Mechanics and Physics of Solids, 45(7):1085-1104, 1997.

G. de Felice. Metodi di omogeneizzazione per sistemi regolari di corpi rigidi. In Proceedings of the XII AIMETA Congress. Naples, Italy, pages 3-6, 1995.

DIANA. Displacement method ANAlyser, 2005. release 9.1, CD-ROM, Netherlands.

L. Gambarotta and S. Lagomarsino. On the dynamic response of masonry walls (in Italian). In Proc. National Congress "La Meccanica delle Murature tra Teoria e Progetto", Messina, 1996.

K. Hellan. Analysis of elastic plates in flexure by a simplified finite element method. Number 46 in Acta polytechnica Scandinavica. Norges tekniske vitenskapsakademi, 1967.

L.R. Herrmann. Finite-element bending analysis for plates. Journal Engineering Mechanics Division, 93:13-26, 1967.

H.K. Hilsdorf. Investigation into the failure mechanism of brick masonry loaded in axial compression. In F.H. Johnson, editor, Designing, engineering and constructing with masonry products, pages 34-41. Gulf Publishing Company, Houston, Texas, 1969.

G. Hoffman and P. Schubert. Compressive strength of masonry parallel to the bed joints. In N.G. Shrive and A. Huizer, editors, Proc. 10th Int. Brick and Block Masonry Conf., pages 1453-1462, Calgary, Alberta, 1994.

K. Krabbenhoft, A.V. Lyamin, M. Hjiaj, and S.W. Sloan. A new discontinuous upper bound limit analysis formulation. International Journal for Numerical Methods in Engineering, 63(7):1069-1088, 2005. 
J. Lopez, S. Oller, E. Onate, and J. Lubliner. A homogeneous constitutive model for masonry. International journal for numerical methods in engineering, 46(10):1651-1671, 1999.

P.B. Lourenço. Computational strategies for masonry structures. $\mathrm{PhD}$ thesis, Delft University of Technology, the Netherlands, 1996. Available from www. civil.uminho.pt/masonry.

P.B. Lourenço. On the use of homogenisation techniques for the analysis of masonry structures. Masonry International, 11(1):26-32, 1997.

P.B. Lourenço. Experimental and numerical issues in the modelling of the mechanical behaviour of masonry. In P. Roca and et al., editors, Proc. Structural analysis of historical constructions II, CIMNE, pages 57-91, Barcelona, 1998a.

P.B. Lourenço. Sensitivity analysis of masonry structures. In Proc. 8th Canadian Masonry Symp., pages 563-574, Jasper, Canada, 1998b.

P.B. Lourenço. Anisotropic softening model for masonry plates and shells. Journal of Structural Engineering, 126(9):1008-1016, 2000.

P.B. Lourenço. Computations on historic masonry structures. Progress in Structural Engineering and Materials, 4(3):301-319, 2002.

P.B. Lourenço and J.L. Pina-Henriques. Validation of analytical and continuum numerical methods for estimating the compressive strength of masonry. Computers \& structures, 84(29):1977-1989, 2006.

P.B. Lourenço and L.F. Ramos. Characterization of cyclic behavior of dry masonry joints. Journal of Structural Engineering, 130(5):779-786, 2004.

P.B. Lourenço and J.G. Rots. A multi-surface interface model for the analysis of masonry structures. Journal of engineering mechanics, 123(7): 660-668, 1997.

P.B. Lourenço, J.O. Barros, and J.T. Oliveira. Shear testing of stack bonded masonry. Construction and Building Materials, 18(2):125-132, 2004.

P.B. Lourenço, J.C. Almeida, and J.A. Barros. Experimental investigation of bricks under uniaxial tensile testing. Masonry International, 18(1): $11-20,2005$.

P.B. Lourenço, G. Milani, A. Tralli, and A. Zucchini. Analysis of masonry structures: review of and recent trends in homogenization techniques this article is one of a selection of papers published in this special issue on masonry. Canadian Journal of Civil Engineering, 34(11):1443-1457, 2007.

P.B. Lourenço, N. Mendes, L.F. Ramos, and D.V. Oliveira. Analysis of masonry structures without box behavior. International Journal of Architectural Heritage, 5(4-5):369-382, 2011.

R. Luciano and E. Sacco. Homogenization technique and damage model for old masonry material. International Journal of Solids and Structures, 34 (24):3191-3208, 1997. 
G. Magenes and A.D. Fontana. Simplified non-linear seismic analysis of masonry buildings. In Proc. British Masonry Society, number 8, pages 190-195, 1998.

G. Maier, E. Papa, and A. Nappi. On damage and failure of unit masonry. In Proc. Experimental and numerical methods in earthquake engineering, pages 223-245, Brussels and Luxembourg, 1991. Balkema Editions.

R. Marques and P.B. Lourenço. Possibilities and comparison of structural component models for the seismic assessment of modern unreinforced masonry buildings. Computers \& Structures, 89(21):2079-2091, 2011.

T.J. Massart. Multi-scale modeling of damage in masonry structures. $\mathrm{PhD}$ thesis, University of Bruxelles, Belgium, 2003.

T.J. Massart, R.H.J. Peerlings, and M.G.D. Geers. Mesoscopic modeling of failure and damage-induced anisotropy in brick masonry. European Journal of Mechanics-A/Solids, 23(5):719-735, 2004.

N. Mendes. Seismic assessment of ancient masonry buildings: Shaking table tests and numerical analysis. $\mathrm{PhD}$ thesis, University of Minho, Portugal, 2012.

MIBAC 2007. Guidelines for the evaluation and mitigation of seismic risk to cultural heritage. Ministry for Cultural Heritage and Activities, Gangemi Editore, Rome, Italy, 2007.

G. Milani. Simple lower bound limit analysis homogenization model for in-and out-of-plane loaded masonry walls. Construction and Building Materials, 25(12):4426-4443, 2011.

G. Milani, P.B. Lourenço, and A. Tralli. Homogenised limit analysis of masonry walls, part I: Failure surfaces. Computers 83 structures, 84(34):166-180, 2006a.

G. Milani, P.B. Lourenço, and A. Tralli. Homogenised limit analysis of masonry walls, part II: Structural examples. Computers \& structures, 84 (3-4):181-195, 2006b.

G. Milani, P.B. Lourenço, and A. Tralli. Homogenization approach for the limit analysis of out-of-plane loaded masonry walls. Journal of structural engineering, 132(10):1650-1663, 2006c.

J. Munro and A.M.A. da Fonseca. Yield line method by finite elements and linear programming. Structural Engineer, 56(2), 1978.

P.C. Olsen. The influence of the linearisation of the yield surface on the load-bearing capacity of reinforced concrete slabs. Computer methods in applied mechanics and engineering, 162(1):351-358, 1998.

OPCM 3431 . Technical regulations for the design, assessment and seismic adaptation of buildings. Gazzetta Ufficiale Serie Generale n.107 del 10/05/2005, Italy, 2005.

G.N. Pande, J.X. Liang, and J. Middleton. Equivalent elastic moduli for brick masonry. Computers and Geotechnics, 8(3):243-265, 1989. 
M. Paulo-Pereira. Assessment of the seismic performance of building enclosures (in Portuguese). PhD thesis, University of Minho, Portugal, 2012.

P. Pegon and A. Anthoine. Numerical strategies for solving continuum damage problems with softening: application to the homogenization of masonry. Computers \& structures, 64(1):623-642, 1997.

PIET-70. P.I.E.T. 70 Masonry work. Prescriptions from Instituto Eduardo Torroja. Consejo Superior de Investigaciones Científicas, Madrid (in Spanish), 1971.

S. Pietruszczak and X. Niu. A mathematical description of macroscopic behaviour of brick masonry. International journal of solids and structures, 29(5):531-546, 1992.

T.M.J. Raijmakers and A.T. Vermeltfoort. Deformation controlled tests in masonry shear walls. Report B-92, 1156, 1992. TNO-Bouw,Delft, The Netherlands (in Dutch).

J.G. Rots, editor. Structural masonry: An experimental/numerical basis for practical design rules. Balkema, Rotterdam, the Netherlands, 1997.

P. Schubert. The influence of mortar on the strength of masonry. In J.W. de Courcy, editor, Proc. 8th Int. Brick and Block Masonry Conf., pages 162-174, London, 1988. Elsevier Applied Science.

S.W. Sloan. Lower bound limit analysis using finite elements and linear programming. International Journal for Numerical and Analytical Methods in Geomechanics, 12(1):61-77, 1988.

S.W. Sloan and P.W. Kleeman. Upper bound limit analysis using discontinuous velocity fields. Computer Methods in Applied Mechanics and Engineering, 127(1):293-314, 1995.

P. Suquet. Analyse limite et homogeneisation. Comptes Rendus de l'Academie des Sciences-Series IIB-Mechanics, 296:1355-1358, 1983.

D.J. Sutcliffe, H.S. Yu, and A.W. Page. Lower bound limit analysis of unreinforced masonry shear walls. Computers \& Structures, 79(14):1295$1312,2001$.

M. Tomazevic. Earthquake-resistant design of masonry buildings. Imperial College Press, London, 1999.

R. van der Pluijm. Out-of-plane bending of masonry: Behavior and Strenght. PhD thesis, Eindhoven University of Technology, The Netherlands, 1999.

G. Vasconcelos and P.B. Lourenço. In-plane experimental behavior of stone masonry walls under cyclic loading. Journal of structural engineering, 135(10):1269-1277, 2009.

G. Vasconcelos, P.B. Lourenço, C.A.S. Alves, and J. Pamplona. Experimental characterization of the tensile behaviour of granites. International journal of rock mechanics and mining sciences, 45(2):268-277, 2008. 
A. Zucchini and P.B. Lourenço. A micro-mechanical model for the homogenisation of masonry. International Journal of Solids and Structures, 39(12):3233-3255, 2002.

A. Zucchini and P.B. Lourenço. A coupled homogenisation-damage model for masonry cracking. Computers \& structures, 82(11):917-929, 2004. 



\section{Contents}

1 Homogenization Theory, Basic Assumptions 1

1.1 Closed-form and simplified solutions in the linear elastic range . . . . . . . . . . . . . . . . . 4

1.2 Simplified stress assumed FE discretization . . . . . . . . . . 9

1.3 Linear elastic case . . . . . . . . . . . . . . . . . . 12

1.4 Constant Stress Triangular elements discretization of the unit cell . . . . . . . . . . . . . . . . . . . 14

1.5 Homogenized failure surfaces . . . . . . . . . . . . . 17

1.6 Out-of-plane homogenized failure surfaces . . . . . . . . . . 30

2 Structural Level $\quad 32$

2.1 In-plane loads: shear wall with central opening . . . . . . . . 32

2.2 Out-of-plane loads: windowed panel in two-way bending . . . 33

3 Dynamics and Seismic Behaviour 36

3.1 Masonry structures with box behaviour . . . . . . . . . 36

3.2 Masonry structures without box behaviour . . . . . . . . . . 39

4 Conclusions $\quad 43$

$\begin{array}{ll}\text { Bibliography } & 44\end{array}$ 